\title{
Popular Benchmark Problems for Geometric Nonlinear Analysis of Shells
}

\author{
K.Y.Sze ${ }^{1 *}$, X.H.Liu ${ }^{1 \#}$, S.H.Lo ${ }^{2}$ \\ Departments of Mechanical ${ }^{1}$ and Civil Engineering ${ }^{2}$ \\ The University of Hong Kong, Pokfulam Road, Hong Kong SAR, P.R.CHINA.
}

\begin{abstract}
In most, if not all, of the previous work on finite element formulation and nonlinear solution procedures, results of geometric nonlinear benchmark problems of shells are presented in the form of load-deflection curves. In this paper, eight sets of popularly employed benchmark problems are identified and their detailed reference solutions are obtained and tabulated. It is hoped that these solutions will form a convenient basis for subsequent comparison and that the tedious yet inaccurate task of reconstructing data points by graphical measurement of previously reported load-deflection curves can be avoided. Moreover, the relative convergent difficulty of the problems are revealed by the number of load increments and the total number of iterations required by an automatic load incrementation scheme for attaining the converged solutions under the maximum loads.
\end{abstract}

* corresponding author, email address : kysze@hku.hk

keywords : finite element, geometric nonlinear, benchmark, shell

\# on leave from Department of Mechanics, Huazhong University of Science \& Technology, Wuhan 430074, P.R.China.

Published in Finite Elements in Analysis \& Design 40: 1551-1569 (2004). 


\section{INTRODUCTION}

To examine or demonstrate the accuracy of new finite element models or the effectiveness of new nonlinear solution procedures, popular benchmark problems are often exercised and the predictions are compared to some reference solutions. Since analytical solutions of shell problems are very limited, most of reference solutions are previously reported numerical solutions. For linear benchmark problems, these solutions can be conveniently and concisely expressed in terms of numerical figures. To this end, the problem sets stipulated by MacNeal \& Harder [1] and Hitchings, Kamoulakos \& Davies [2] include some of the most widely attempted tests. Reference [1] has been well-received in the academic community. Reference [2] is a publication of UK's National Agency for Finite Element Methods and Standards (NAFEMS) and is mainly adopted by software developers for quality assurance. Noticeably, there are a number of cases common to both problem sets.

For geometric nonlinear analysis of shells, the most recent and relevant NAFEMS publication is probably the one by Prinja \& Clegg [3]. Besides reference [3], more than forty research papers [449] on geometric nonlinear finite element formulation have also been surveyed. For conciseness, the reported predictions are mostly presented in the form of load-deflection curves. Occasionally, the results are reported numerically at a few selected load levels. In order to compare the predictions of new finite element models or procedures with their precedents, reconstructing the previously reported load-deflection curves by extracting data points using graphical measurement is the obvious and, perhaps, the only choice. The practice is not only inaccurate but also time consuming. In this context, eight sets of popular benchmark problems for geometric nonlinear analysis of shell are selected from those considered in references [3-49]. They are attempted by using ABAQUS's S4R four-node shell element models [50]. This paper will provide sufficient data points in numerical format so that the relevant load-deflection curves can be accurately and efficiently reconstructed. To reveal the relative convergent difficulty of the problems, the number of load increments and the total number of iterations required by ABAQUS's default automatic load incrementation scheme for attaining the converged solutions under the maximum loads are reported.

\section{LOAD INCREMENTATION SCHEME}

In the nonlinear solution procedure, the full Newton-Raphson method is used. The default convergence criteria are always employed and they are the simultaneous $0.5 \%$ force tolerance and $1 \%$ displacement tolerance. The default automatic load incrementation scheme in ABAQUS is adopted and the procedure is portrayed in Figure 1. Throughout the scheme, the maximum load $\mathrm{P}_{\max }$ 
will be automatically subdivided into NINC load increments which are not necessarily uniform. At the end of each load increment, a converged intermediate solution is obtained. This reduces the degree of nonlinearity from an intermediate solution state to another and enhances the chance of obtaining the ultimate solution. The latter is the one under the maximum load $\mathrm{P}_{\max }$. The scheme starts with the load increment $\Delta \mathrm{P}$ set to the maximum load $\mathrm{P}_{\max }$. If the solution cannot converge within 16 iterations (counted by $\mathrm{m}$ ) or if the solution diverges, the scheme abandons the increment and starts again with the load increment reduced to one-quarter of the previous value. If the solution still fails to converge, the scheme further reduces the increment size again. If the solution fails after 5 attempts (counted by n) of load increment reduction, the analysis will be stopped or aborted. On the other hand, it automatically increases the load increment by $50 \%$ if the last two converged solutions are both obtained within 5 iterations. If the scheme is not aborted, ABAQUS outputs NINC and NITER. The latter is the total number of iterations required to obtained the NINC converged intermediate solutions. In this paper, both NINC and NITER are reported to reveal the relative convergent difficulty of the considered problems.

For the sake of benchmarking, intermediate solutions given at uniform load intervals are desired. However, these solutions cannot be yielded by the afore-discussed default automatic load incrementation scheme. To this end, the solutions to be reported are computed by dividing the maximum load into a number of equal load increments NINC*, where further subdivision of the load increment is suppressed. In order that the ultimate solution can be successfully obtained, NINC* is often much larger than the NINC required by the default automatic load incrementation scheme.

\section{BENCHMARK TESTS}

In this section, eight sets of popularly employed geometric nonlinear benchmark problems on beams, plates, cylindrical shells and spherical shell are selected. A small portion of the considered structures are laminated. In the subsequent description, the following nomenclature is employed:
v: Poisson's ratio
b: width
E: elastic modulus
$\mathrm{G}$ : shear modulus
$\mathrm{h}$ : thickness of beam, plate or shell
I: second moment of area
L: length or longitudinal length

$\mathrm{M}, \mathrm{M}_{\max }$ : applied moment and maximum applied moment, respectively

NINC: the total number of load increments that yield the ultimate solution (determined by the default load incrementation scheme), 
NINC*: the number of equal load increments used to obtain the plotted and tabulated data

NITER: the total number of iterations that lead to the NINC convergent solutions

$\mathrm{P}, \mathrm{P}_{\max }$ : applied force and maximum applied force, respectively

$\mathrm{R}$ : mean radius

$\mathrm{U}, \mathrm{V}$ and $\mathrm{W}$ : displacements along the Cartesian coordinates $\mathrm{X}, \mathrm{Y}$ and $\mathrm{Z}$, respectively.

All benchmark problems to be presented have been attempted by ABAQUS's S4R, S4R5 and S9R5 curved shell element models. All of them are Reduced-integrated elements with hourglass control and their features are summarized in Table 1. In particular, the formulation of S4R changes when the shell thickness increases from that of the discrete Kirchhoff shell to that of the thick shell. On the other hand, both S4R5 and S9R5 are only recommended for thin shell analysis [50]. In nearly all problems, the deformed structures will be portrayed and the displacement amplification factor is always taken to be unity.

Table 1. Features of S4R, S4R5 and S9R5 curved shell element models.

\begin{tabular}{|l|c|c|c|}
\hline & S4R & S4R5 & S9R5 \\
\hline No. of nodes per element & 4 & 4 & 9 \\
\hline No. of d.o.f.s per node & 6 & 5 & 5 \\
\hline Hourglass treatment & default stabilization & default stabilization & default stabilization \\
\hline Drilling rotation treatment & default stabilization & not applicable & not applicable \\
\hline Lagrangian framework & updated & total & total \\
\hline Applicable strain & finite/large & small & small \\
\hline Intended thickness & thin and thick & thin only & thin only \\
\hline
\end{tabular}

When the default automatic load incrementation scheme is adopted, the solution procedures of S4R5 are aborted before the load reaches its maximum in many benchmark problems. The situation of S9R5 is even worse. When equal load increments are imposed, S4R5 and S9R5 require considerably larger number of load increments than that of S4R for securing the ultimate solution. In this light, only the predictions of S4R and the related NINC and NITER output at the end of the automatic load incrementation scheme will be reported.

To ensure that the reported solutions have been sufficiently converged with respect to the mesh density, the mesh is refined until the solutions yielded by two successively refined meshes are practically identical. To illustrate that the mesh density is adequate, results predicted by two different meshes will be shown in all load-deflection curves. The two sets of results are graphically indistinguishable and the discrepancy is typically around $0.1 \%$. The precise relations between the applied loads and the selected deflections in numerical format are mostly reported at a load interval given as $5 \%$ of the maximum load. If deemed to be necessary, additional data points are employed to enhance the quality of the so-constructed load-deflection curves. Lastly, all problems are geometric nonlinear in the narrow sense and material nonlinearity is not considered. 


\subsection{Cantilever subjected to End Shear Force}

Figure 2a shows a cantilever subjected to the end shear force P. The problem has been considered in references $[5,8,19,21,29,32,35,36,45,47,48]$, among others. A commonly employed mesh for four-node shell elements is $8 \times 1$ which is also adequate for the S4R element. Figure $2 \mathrm{~b}$ plots the end shear force against the vertical and horizontal tip deflections. Table 2a lists the same deflections whereas Table $2 b$ lists the NINC and NITER. Figure $2 \mathrm{c}$ portrays the deformed cantilever under the maximum load.

Table 2a. Horizontal and vertical tip deflections for the cantilever loaded with end shear force (computed by using $16 \times 1$ S4R elements and $\mathrm{NINC}^{*}=40$ ), see Figure 2a.

\begin{tabular}{|c|cc|c|cc|c|cc|}
\hline $\mathrm{P} / \mathrm{P}_{\max }$ & $-\mathrm{U}_{\text {tip }}$ & $\mathrm{W}_{\text {tip }}$ & $\mathrm{P}_{\mathrm{P}}$ & $-\mathrm{U}_{\text {tip }}$ & $\mathrm{W}_{\text {tip }}$ & $\mathrm{P} / \mathrm{P}_{\mathrm{o}}$ & $-\mathrm{U}_{\text {tip }}$ & $\mathrm{W}_{\text {tip }}$ \\
\hline 0.05 & 0.026 & 0.663 & 0.40 & 1.184 & 4.292 & 0.75 & 2.541 & 6.031 \\
0.10 & 0.103 & 1.309 & 0.45 & 1.396 & 4.631 & 0.80 & 2.705 & 6.190 \\
0.15 & 0.224 & 1.922 & 0.50 & 1.604 & 4.933 & 0.85 & 2.861 & 6.335 \\
0.20 & 0.381 & 2.493 & 0.55 & 1.807 & 5.202 & 0.90 & 3.010 & 6.467 \\
0.25 & 0.563 & 3.015 & 0.60 & 2.002 & 5.444 & 0.95 & 3.151 & 6.588 \\
0.30 & 0.763 & 3.488 & 0.65 & 2.190 & 5.660 & 1.00 & 3.286 & 6.698 \\
0.35 & 0.971 & 3.912 & 0.70 & 2.370 & 5.855 & & & \\
\hline
\end{tabular}

Table 2b. NINCs and NITERs required to obtained the ultimate solution for the cantilever loaded with end shear force, see Figure 2a.

\begin{tabular}{|c|cc|}
\hline & $8 \times 1$ S4R elements & $16 \times 1$ S4R elements \\
\hline NINC & 15 & 15 \\
NITER & 78 & 80 \\
\hline
\end{tabular}

\subsection{Cantilever subjected to End Moment}

Figure 3a shows a cantilever subjected to end moment M. A commonly employed mesh for fournode shell elements is $12 \times 1$. The problem has been considered in references [5,10,13,17,18,21,29, $30,32,34,36,40,46]$, among others. The cantilever forms a circular arc with its radius $\mathrm{R}$ given by the classical flexural formula $R=E I / M$. Using the formula, the analytical normalized deflections can be derived to be

$$
\frac{U}{L}=\frac{M_{o}}{M} \sin \frac{M}{M_{o}}-1, \frac{W}{L}=\frac{M_{o}}{M}\left(1-\cos \frac{M}{M_{o}}\right)
$$

where $\mathrm{M}_{\mathrm{o}}=\mathrm{EI} / \mathrm{L}$. The maximum end moment $\mathrm{M}_{\max }$ is taken to be $\pi \mathrm{M}_{\mathrm{o}}$ at which the beam will be bent into a circle. In this problem, accurate predictions can be yielded by $8 \times 1 \mathrm{~S} 4 \mathrm{R}$ elements. Figure $3 \mathrm{~b}$ plots the end moment against the vertical and horizontal tip deflections. Figure $3 \mathrm{c}$ portrays the 
deformed cantilevers at $\mathrm{M}=0.35 \mathrm{M}_{\max }, 0.7 \mathrm{M}_{\max }$ and $\mathrm{M}_{\max }$. Table 3a lists the analytical and computed tip deflections, which are highly consistent with each other. Table $3 \mathrm{~b}$ lists the NINC and NITER. Compared to the last cantilever problem, the present one converges less readily.

Table 3a. Horizontal and vertical tip deflections for the cantilever loaded with end bending moment (computed by using $16 \times 1$ S4R elements and NINC* $=80$ ), see Figure $3 \mathrm{a}$.

\begin{tabular}{|c|cc|cc|c|cc|cc|}
\hline \multirow{2}{*}{$\mathrm{M} / \mathrm{M}_{\max }$} & \multicolumn{2}{|c|}{$-\mathrm{U}_{\text {tip }}$} & \multicolumn{2}{|c|}{$\mathrm{W}_{\text {tip }}$} & \multirow{2}{*}{$\mathrm{M} / \mathrm{M}_{\max }$} & \multicolumn{2}{|c|}{$-\mathrm{U}_{\text {tip }}$} & \multicolumn{2}{|c|}{$\mathrm{W}_{\text {tip }}$} \\
\cline { 2 - 6 } & $\mathrm{S} 4 \mathrm{R}$ & exact & $\mathrm{S} 4 \mathrm{R}$ & exact & & $\mathrm{S} 4 \mathrm{R}$ & exact & $\mathrm{S} 4 \mathrm{R}$ & exact \\
\hline 0.05 & 0.196 & 0.196 & 1.870 & 1.870 & 0.55 & 13.075 & 13.073 & 6.788 & 6.775 \\
0.10 & 0.773 & 0.774 & 3.648 & 3.648 & 0.60 & 13.875 & 13.871 & 5.772 & 5.758 \\
0.15 & 1.698 & 1.699 & 5.249 & 5.248 & 0.65 & 14.384 & 14.377 & 4.678 & 4.665 \\
0.20 & 2.916 & 2.918 & 6.600 & 6.598 & 0.70 & 14.603 & 14.595 & 3.583 & 3.571 \\
0.25 & 4.357 & 4.361 & 7.643 & 7.639 & 0.75 & 14.556 & 14.546 & 2.556 & 2.546 \\
0.30 & 5.942 & 5.945 & 8.338 & 8.333 & 0.80 & 14.280 & 14.270 & 1.656 & 1.650 \\
0.35 & 7.582 & 7.585 & 8.671 & 8.664 & 0.85 & 13.826 & 13.818 & 0.931 & 0.926 \\
0.40 & 9.191 & 9.194 & 8.646 & 8.637 & 0.90 & 13.254 & 13.247 & 0.407 & 0.405 \\
0.45 & 10.687 & 10.688 & 8.291 & 8.281 & 0.95 & 12.625 & 12.621 & 0.099 & 0.098 \\
0.50 & 12.000 & 12.000 & 7.652 & 7.639 & 1.00 & 12.000 & 12.000 & 0.000 & 0.000 \\
\hline
\end{tabular}

Table 3b. NINCs and NITERs required to obtain the ultimate solution for the cantilever loaded with end bending moment, see Figure $3 \mathrm{a}$.

\begin{tabular}{|c|cc|}
\hline & $8 \times 1$ S4R elements & $16 \times 1$ S4R elements \\
\hline NINC & 125 & 125 \\
NITER & 715 & 714 \\
\hline
\end{tabular}

\subsection{Slit Annular Plate subjected to Lifting Line Force}

The slit annular plate is shown in Figure 4a. The problem has been considered in references $[23,25,27,33,36,39,40,44,46,48,49]$, among others. The line force $\mathrm{P}$ is applied at one end of the slit while the other end of the slit is fully clamped. A commonly employed mesh for four-node shell elements is $6 \times 30$ which is also adequate for the S4R element. Figure $4 \mathrm{~b}$ plots the load against the vertical deflections at the tips of the slit $\mathrm{A}$ and $\mathrm{B}$. Table $4 \mathrm{a}$ lists the deflections whereas Table $4 \mathrm{~b}$ lists the NINC and NITER. Figure 4c shows the deformed slit plate under the maximum load.

Table 4a. Vertical deflections at points A and B of the slit annular plate lifted by a line force $(10 \times 80$ S4R elements and NINC* $=640)$, see Figure $4 \mathrm{a}$.

\begin{tabular}{|c|cc|c|cc|c|cc|}
\hline $\mathrm{P} / \mathrm{P}_{\max }$ & $\mathrm{W}_{\mathrm{A}}$ & $\mathrm{W}_{\mathrm{B}}$ & $\mathrm{P} / \mathrm{P}_{\max }$ & $\mathrm{W}_{\mathrm{A}}$ & $\mathrm{W}_{\mathrm{B}}$ & $\mathrm{P} / \mathrm{P}_{\max }$ & $\mathrm{W}_{\mathrm{A}}$ & $\mathrm{W}_{\mathrm{B}}$ \\
\hline 0.025 & 1.305 & 1.789 & 0.30 & 8.340 & 11.213 & 0.70 & 11.970 & 15.469 \\
0.05 & 2.455 & 3.370 & 0.35 & 8.974 & 11.992 & 0.75 & 12.310 & 15.842 \\
0.075 & 3.435 & 4.720 & 0.40 & 9.529 & 12.661 & 0.80 & 12.642 & 16.202 \\
0.10 & 4.277 & 5.876 & 0.45 & 10.023 & 13.247 & 0.85 & 12.966 & 16.550 \\
0.125 & 5.007 & 6.872 & 0.50 & 10.468 & 13.768 & 0.90 & 13.282 & 16.886 \\
0.15 & 5.649 & 7.736 & 0.55 & 10.876 & 14.240 & 0.95 & 13.590 & 17.212 \\
0.20 & 6.725 & 9.160 & 0.60 & 11.257 & 14.674 & 1.00 & 13.891 & 17.528 \\
0.25 & 7.602 & 10.288 & 0.65 & 11.620 & 15.081 & & & \\
\hline
\end{tabular}


Table 4b. NINCs and NITERs required to obtain the ultimate solution for slit annular plate lifted by line force, see Figure $4 a$.

\begin{tabular}{|c|cc|}
\hline & $6 \times 30$ S4R elements & $10 \times 80$ S4R elements \\
\hline NINC & 61 & 67 \\
NITER & 327 & 346 \\
\hline
\end{tabular}

\subsection{Hemispherical Shell subjected to Alternating Radial Forces}

Figure 5a shows hemispherical shell with an $18^{\circ}$ circular cutout at its pole. The shell is loaded by alternating radial point forces Ps at $90^{\circ}$ intervals. The problem has been considered in references [18,19,21,23,25,26,28,31,32,34,35,37,40,41,44-49], among others. Owing to symmetry, one quarter of the shell is modeled and a commonly employed mesh for four-node shell elements is $16 \times 16$. Figure $5 \mathrm{~b}$ plots the load against the radial deflections at the points of loading A and B. Table 5a lists the same deflections whereas Table 5b lists the NINC and NITER. Figure 5a also shows the deformed hemispherical shell under the maximum load. In this problem, reasonably accurate predictions can be yielded by using $12 \times 12$ S4R elements.

Table 5a. Radial deflections at points A and B of the hemispherical shell problem (computed by $16 \times 16$ S4R elements and NINC* $=40$ ), see Figure 5a.

\begin{tabular}{|c|cc|c|cc|c|cc|}
\hline $\mathrm{P} / \mathrm{P}_{\max }$ & $\mathrm{V}_{\mathrm{A}}$ & $-\mathrm{U}_{\mathrm{B}}$ & $\mathrm{P} / \mathrm{P}_{\max }$ & $\mathrm{V}_{\mathrm{A}}$ & $-\mathrm{U}_{\mathrm{B}}$ & $\mathrm{P} / \mathrm{P}_{\max }$ & $\mathrm{V}_{\mathrm{A}}$ & $-\mathrm{U}_{\mathrm{B}}$ \\
\hline 0.05 & 0.855 & 0.955 & 0.40 & 3.158 & 5.196 & 0.75 & 3.816 & 7.234 \\
0.10 & 1.499 & 1.840 & 0.45 & 3.291 & 5.565 & 0.80 & 3.875 & 7.448 \\
0.15 & 1.969 & 2.604 & 0.50 & 3.406 & 5.902 & 0.85 & 3.929 & 7.647 \\
0.20 & 2.321 & 3.261 & 0.55 & 3.508 & 6.212 & 0.90 & 3.979 & 7.835 \\
0.25 & 2.596 & 3.833 & 0.60 & 3.598 & 6.497 & 0.95 & 4.025 & 8.011 \\
0.30 & 2.819 & 4.339 & 0.65 & 3.678 & 6.761 & 1.00 & 4.067 & 8.178 \\
0.35 & 3.002 & 4.790 & 0.70 & 3.750 & 7.006 & & & \\
\hline
\end{tabular}

Table 5b. NINCs and NITERs required to obtain the ultimate solution for the hemisphere shell problem, see Figure 5a.

\begin{tabular}{|c|cc|}
\hline & $12 \times 12$ S4R elements & $16 \times 16$ S4R elements \\
\hline NINC & 27 & 27 \\
NITER & 140 & 136 \\
\hline
\end{tabular}

\subsection{Pullout of an Open-Ended Cylindrical Shell}

Figure 6a shows an open-ended cylinder being pulled by a pair of radial forces Ps. The problem has been considered in references [14,24,26,28,32,33,40,44,46,48,49], among others. Owing to symmetry, one-eighth of the shell is modeled and a commonly employed mesh for four-node shell elements is $8 \times 12$. Figure 6 b plots the load against the radial deflections at points $\mathrm{A}, \mathrm{B}$ and $\mathrm{C}$. Table 6a lists the data points whereas Table $6 \mathrm{~b}$ lists the NINC and NITER. The deformed geometry under the maximum load is portrayed in Figure 6c. In this problem, reasonably accurate predictions can 
be yielded by $16 \times 24$ S4R elements.

Table 6a. Radial deflections at points A, B and C of the open-ended cylindrical shell (computed by using $24 \times 36$ S4R elements and NINC* $=400$ ), see Figure 6 a.

\begin{tabular}{|c|ccc|c|ccc|cccc|}
\hline $\mathrm{P} / \mathrm{P}_{\max }$ & $\mathrm{W}_{\mathrm{A}}$ & $-\mathrm{U}_{\mathrm{B}}$ & $-\mathrm{U}_{\mathrm{C}}$ & $\mathrm{P} / \mathrm{P}_{\max }$ & $\mathrm{W}_{\mathrm{A}}$ & $-\mathrm{U}_{\mathrm{B}}$ & $-\mathrm{U}_{\mathrm{C}}$ & $\mathrm{P} / \mathrm{P}_{\max }$ & $\mathrm{W}_{\mathrm{A}}$ & $-\mathrm{U}_{\mathrm{B}}$ & $-\mathrm{U}_{\mathrm{C}}$ \\
\hline 0.025 & 0.819 & 0.864 & 0.872 & 0.35 & 2.321 & 3.342 & 3.556 & 0.70 & 2.672 & 4.385 & 3.378 \\
0.05 & 1.260 & 1.471 & 1.493 & 0.40 & 2.376 & 3.443 & 3.632 & 0.75 & 2.692 & 4.423 & 3.353 \\
0.075 & 1.527 & 1.901 & 1.946 & 0.45 & 2.425 & 3.539 & 3.688 & 0.80 & 2.710 & 4.455 & 3.332 \\
0.10 & 1.707 & 2.217 & 2.293 & 0.50 & 2.473 & 3.653 & 3.718 & 0.85 & 2.726 & 4.483 & 3.313 \\
0.15 & 1.936 & 2.641 & 2.792 & 0.525 & 2.543 & 4.061 & 3.580 & 0.90 & 2.741 & 4.508 & 3.297 \\
0.20 & 2.079 & 2.904 & 3.106 & 0.55 & 2.577 & 4.171 & 3.518 & 0.95 & 2.755 & 4.530 & 3.283 \\
0.25 & 2.180 & 3.087 & 3.310 & 0.60 & 2.618 & 4.274 & 3.452 & 1.00 & 2.768 & 4.551 & 3.269 \\
0.30 & 2.257 & 3.227 & 3.452 & 0.65 & 2.648 & 4.338 & 3.410 & & & & \\
\hline
\end{tabular}

Table 6b. NINCs and NITERs required to obtain the ultimate solution for the open-ended cylindrical shell, see Figure $6 \mathrm{a}$.

\begin{tabular}{|c|cc|}
\hline & $16 \times 24$ S4R elements & $24 \times 36$ S4R elements \\
\hline NINC & 18 & 18 \\
NITER & 91 & 94 \\
\hline
\end{tabular}

\subsection{Pinched Cylindrical Shell mounted over Rigid Diaphragms}

Figure 7a shows a pinched cylindrical shell mounted on rigid end diaphragms over which the in-plane displacements $\mathrm{U}$ and $\mathrm{W}$ are restrained. The problem and its variations have been considered in references [21,26,37,43-45,48], among others. Owing to symmetry, one-eighth of the shell is modeled and a commonly employed mesh for four-node shell elements is $40 \times 40$ which is also adequate for the S4R element. Figure $7 \mathrm{~b}$ plots the load against radial deflections at points A and B. Table $7 \mathrm{a}$ lists the same deflections whereas Table $7 \mathrm{~b}$ lists the NINC and NITER. The deformed geometry under the maximum load is portrayed in Figure $7 \mathrm{c}$.

Table 7a. Radial deflections at points A and B of the pinched cylindrical shell (computed by $48 \times 48$ S4R elements and NINC* $=1280$ ), see Figure 7a.

\begin{tabular}{|c|cc|c|cc|c|cc|}
\hline $\mathrm{P} / \mathrm{P}_{\max }$ & $-\mathrm{W}_{\mathrm{A}}$ & $\mathrm{U}_{\mathrm{B}}$ & $\mathrm{P} / \mathrm{P}_{\max }$ & $-\mathrm{W}_{\mathrm{A}}$ & $\mathrm{U}_{\mathrm{B}}$ & $\mathrm{P} / \mathrm{P}_{\max }$ & $-\mathrm{W}_{\mathrm{A}}$ & $\mathrm{U}_{\mathrm{B}}$ \\
\hline 0.05 & 9.561 & -0.233 & 0.30 & 65.498 & 17.979 & 0.70 & 78.451 & 29.772 \\
0.075 & 15.648 & -0.922 & 0.35 & 68.229 & 20.365 & 0.75 & 79.339 & 30.604 \\
0.10 & 23.164 & -2.391 & 0.40 & 70.424 & 22.321 & 0.80 & 80.218 & 31.471 \\
0.125 & 29.375 & -3.872 & 0.45 & 72.204 & 23.916 & 0.85 & 81.045 & 32.299 \\
0.15 & 36.208 & -2.154 & 0.50 & 73.790 & 25.381 & 0.90 & 81.766 & 32.989 \\
0.175 & 51.499 & 6.792 & 0.55 & 75.139 & 26.631 & 0.95 & 82.435 & 33.619 \\
0.20 & 56.373 & 10.448 & 0.60 & 76.331 & 27.735 & 1.00 & 83.102 & 34.272 \\
0.25 & 61.877 & 14.905 & 0.65 & 77.472 & 28.843 & & & \\
\hline
\end{tabular}


Table 7b. NINCs and NITERs required to obtain the ultimate solution for the pinched cylindrical shell, see Figure $7 \mathrm{a}$.

\begin{tabular}{|c|cc|}
\hline & $40 \times 40$ S4R elements & $48 \times 48$ S4R elements \\
\hline NINC & 69 & 70 \\
NITER & 391 & 406 \\
\hline
\end{tabular}

\subsection{Pinched Semi-Cylindrical Isotropic and Laminated Shells}

Figure $8 \mathrm{a}$ shows the semi-cylindrical shell subjected to an end pinching force at the middle of the free-hanging circumferential periphery. The other circumferential periphery is fully clamped. Along its longitudinal edges, the vertical deflection and the rotation about the Y-axes are restrained. Besides the isotropic material, laminates with stacking sequences $\left[0^{\circ} / 90^{\circ} / 0^{0}\right]$ and $\left[90^{\circ} / 0^{\circ} / 90^{\circ}\right]$ are also considered. In the laminates, all plies are equal in thickness. A ply is of $0^{0}$ if its fibres are parallel to the longitudinal direction of the shell. The present problems have been considered in references [16,22,33,40,42,47,48], among others. Owing to symmetry, half of shell is modeled and a commonly employed mesh for four-node shell elements is $16 \times 16$. Figure $8 \mathrm{~b}$ plots the applied force against the downward deflections at A. Table 8a lists the same deflections whereas Table $8 \mathrm{~b}$ lists the NINC and NITER. The deformed shells under the maximum load are portrayed in Figures $8 \mathrm{c}$ and $8 \mathrm{~d}$. In this problem, reasonably accurate predictions can be yielded by $32 \times 32 \mathrm{~S} 4 \mathrm{R}$ elements.

Table 8a. The downward deflection at A of the pinched semi-cylindrical shells (computed by using $40 \times 40$ S4R elements and NINC* $=320$ ), see Figure $8 \mathrm{a}$.

\begin{tabular}{|c|ccc|c|ccc|}
\hline $\mathrm{P} / \mathrm{P}_{\max }$ & isotropic & {$\left[0^{0} / 90^{0} / 0^{0}\right]$} & {$\left[90^{0} / 0^{0} / 90^{0}\right]$} & $\mathrm{P} / \mathrm{P}_{\max }$ & isotropic & {$\left[0^{0} / 90^{0} / 0^{0}\right]$} & {$\left[90^{0} / 0^{0} / 90^{0}\right]$} \\
\hline 0.05 & 5.421 & 15.340 & 7.558 & 0.45 & 124.751 & 177.404 & 132.488 \\
0.10 & 16.100 & 37.920 & 22.722 & 0.50 & 132.653 & 180.680 & 138.740 \\
0.125 & 22.195 & 55.145 & 30.594 & 0.55 & 138.920 & 183.544 & 144.238 \\
0.15 & 27.657 & 93.433 & 37.897 & 0.60 & 144.185 & 186.099 & 149.191 \\
0.175 & 32.700 & 129.575 & 45.427 & 0.65 & 148.770 & 188.415 & 153.728 \\
0.20 & 37.582 & 141.562 & 54.455 & 0.70 & 152.863 & 190.543 & 157.930 \\
0.225 & 42.633 & 149.034 & 65.814 & 0.75 & 156.584 & 192.520 & 161.854 \\
0.25 & 48.537 & 154.634 & 79.512 & 0.80 & 160.015 & 194.376 & 165.540 \\
0.275 & 56.355 & 159.141 & 92.524 & 0.85 & 163.211 & 196.132 & 169.017 \\
0.30 & 66.410 & 162.896 & 102.357 & 0.90 & 166.200 & 197.808 & 172.308 \\
0.325 & 79.810 & 166.099 & 109.793 & 0.95 & 168.973 & 199.420 & 175.430 \\
0.35 & 94.669 & 168.884 & 115.746 & 1.00 & 171.505 & 200.983 & 178.386 \\
0.40 & 113.704 & 173.560 & 125.094 & & & & \\
\hline
\end{tabular}

Table $8 \mathrm{~b}$. NINCs and NITERs required to obtain the ultimate solution for the pinched semicylindrical, see Figure 8 a.

\begin{tabular}{|c|ccc|ccc|}
\hline & \multicolumn{3}{|c|}{$32 \times 32$ S4R elements } & \multicolumn{3}{c|}{$40 \times 40$ S4R elements } \\
\cline { 2 - 7 } & isotropic & {$\left[0^{0} / 90^{0} / 0^{0}\right]$} & {$\left[90^{0} / 0^{0} / 90^{0}\right]$} & isotropic & {$\left[0^{0} / 90^{0} / 0^{0}\right]$} & {$\left[90^{0} / 0^{0} / 90^{0}\right]$} \\
\hline NINC & 28 & 36 & 32 & 28 & 36 & 33 \\
NITER & 136 & 171 & 184 & 136 & 170 & 184 \\
\hline
\end{tabular}




\subsection{Hinged Cylindrical Isotropic and Laminated Roofs}

Figure 9a shows the hinged semi-cylindrical roof subjected to a central pinching force. An isotropic material, $\left[0^{0} / 90^{0} / 0^{0}\right]$ laminate and $\left[90^{\circ} / 0^{0} / 90^{\circ}\right]$ laminate at two different thicknesses are considered. Again, a ply is of $0^{0}$ if its fibres are parallel to the longitudinal direction of the shell. All plies in the same laminate are equal in thickness. Along the hinged edges, all nodal translations are restrained. These problems have been considered in references [4-12,15,17,18,20,21,24,26,28$30,33,36,38,43,47,48]$, among others, and are particularly popular due to the snapping behavior. At some intermediate state, the tangential global stiffness matrices become singular. The problems are often, if not always, solved by Riks solution method and such an option in ABAQUS is adopted. Owing to symmetry, one quarter of the roof is modeled and a commonly employed mesh for fournode shell elements is $4 \times 4$. For the 12.7 unit thick shells, reasonably accurate predictions can be yielded by using $8 \times 8 \mathrm{~S} 4 \mathrm{R}$ elements as shown in Figure $9 \mathrm{~b}$. For the 6.35 unit thick shells, the same mesh is inadequate. However, reasonably accurate predictions can be obtained by using $16 \times 16 \mathrm{~S} 4 \mathrm{R}$ elements as shown in Figure 9c. Tables 9a to 9f list the data points. With the Riks solution method, it is not possible to yield a solution at a preset load level. This explains why the load levels in the tables are different whereas the load-deflections curves produced by the coarser meshes do not reach the last solution points yielded by the finer meshes in Figures $9 b$ and $9 c$. Despite the high nonlinearity, the maximum deflections are much smaller than the overall dimensions of the roof. Unlike the previous problems, the deformed meshes are not shown as they can hardly be distinguished from the undeformed ones. As the default automatic load incrementation scheme does not work for the present problems, there are no NINC and NITER.

Table 9a. Deflections for the 12.7 unit thick isotropic hinged cylindrical shell (computed by using $16 \times 16$ S4R elements and Riks method), see Figure 9 a.

\begin{tabular}{|cc|cc|cc|cc|}
\hline $\mathrm{P} / \mathrm{P}_{\max }$ & $-\mathrm{W}_{\mathrm{C}}$ & $\mathrm{P} / \mathrm{P}_{\max }$ & $-\mathrm{W}_{\mathrm{C}}$ & $\mathrm{P} / \mathrm{P}_{\max }$ & $-\mathrm{W}_{\mathrm{C}}$ & $\mathrm{P} / \mathrm{P}_{\max }$ & $-\mathrm{W}_{\mathrm{C}}$ \\
\hline 0.0877 & 0.693 & 0.7421 & 11.293 & 0.3245 & 16.590 & 0.3871 & 24.049 \\
0.1980 & 1.638 & 0.7286 & 12.141 & 0.2717 & 17.094 & 0.4443 & 24.663 \\
0.3473 & 3.087 & 0.7023 & 12.903 & 0.2272 & 17.657 & 0.5093 & 25.293 \\
0.4686 & 4.477 & 0.6649 & 13.583 & 0.1940 & 18.299 & 0.5826 & 25.940 \\
0.5647 & 5.802 & 0.6182 & 14.188 & 0.1750 & 19.028 & 0.6644 & 26.601 \\
0.6381 & 7.057 & 0.5643 & 14.728 & 0.1729 & 19.852 & 0.7551 & 27.276 \\
0.6908 & 8.237 & 0.5055 & 15.217 & 0.1905 & 20.771 & 0.8549 & 27.964 \\
0.7246 & 9.339 & 0.4442 & 15.676 & 0.2303 & 21.780 & 0.9643 & 28.663 \\
0.7412 & 10.358 & 0.3830 & 16.125 & 0.2950 & 22.875 & 1.0835 & 29.374 \\
\hline
\end{tabular}


Table 9b. Deflections for the 12.7 unit thick $\left[0^{0} / 90^{0} / 0^{0}\right]$ hinged cylindrical shell (computed by using 16×16 S4R elements and Riks method), see Figure 9a.

\begin{tabular}{|cc|cc|cc|cc|}
\hline $\mathrm{P} / \mathrm{P}_{\max }$ & $-\mathrm{W}_{\mathrm{C}}$ & $\mathrm{P} / \mathrm{P}_{\max }$ & $-\mathrm{W}_{\mathrm{C}}$ & $\mathrm{P} / \mathrm{P}_{\max }$ & $-\mathrm{W}_{\mathrm{C}}$ & $\mathrm{P} / \mathrm{P}_{\max }$ & $-\mathrm{W}_{\mathrm{C}}$ \\
\hline 0.0546 & 0.807 & 0.3577 & 10.735 & 0.0638 & 16.199 & 0.0194 & 22.707 \\
0.1245 & 1.956 & 0.3464 & 11.516 & 0.0303 & 16.648 & 0.0697 & 23.824 \\
0.1938 & 3.281 & 0.3288 & 12.227 & 0.0007 & 17.141 & 0.1354 & 25.005 \\
0.2494 & 4.548 & 0.3057 & 12.872 & -0.0236 & 17.692 & 0.2178 & 26.244 \\
0.2925 & 5.753 & 0.2778 & 13.458 & -0.0411 & 18.317 & 0.3181 & 27.533 \\
0.3244 & 6.892 & 0.2461 & 13.990 & -0.0504 & 19.024 & 0.4374 & 28.864 \\
0.3459 & 7.961 & 0.2115 & 14.477 & -0.0503 & 19.817 & 0.5769 & 30.229 \\
0.3582 & 8.959 & 0.1749 & 14.928 & -0.0394 & 20.698 & 0.7374 & 31.622 \\
0.3618 & 9.884 & 0.0999 & 15.774 & -0.0165 & 21.663 & 1.0192 & 33.748 \\
\hline
\end{tabular}

Table 9c. Deflections for the 12.7 unit thick $\left[90^{\circ} / 0^{0} / 90^{0}\right]$ hinged cylindrical shell (computed by using $16 \times 16$ S4R elements and Riks method), see Figure 9a.

\begin{tabular}{|cc|cc|cc|cc|}
\hline $\mathrm{P} / \mathrm{P}_{\max }$ & $-\mathrm{W}_{\mathrm{C}}$ & $\mathrm{P} / \mathrm{P}_{\max }$ & $-\mathrm{W}_{\mathrm{C}}$ & $\mathrm{P} / \mathrm{P}_{\max }$ & $-\mathrm{W}_{\mathrm{C}}$ & $\mathrm{P} / \mathrm{P}_{\max }$ & $-\mathrm{W}_{\mathrm{C}}$ \\
\hline 0.0556 & 0.649 & 0.5336 & 9.545 & 0.5801 & 16.019 & 0.2834 & 20.881 \\
0.1299 & 1.581 & 0.5550 & 10.404 & 0.5685 & 16.545 & 0.2789 & 21.318 \\
0.2090 & 2.673 & 0.5716 & 11.231 & 0.5542 & 17.028 & 0.2812 & 21.823 \\
0.2784 & 3.740 & 0.5838 & 12.024 & 0.5374 & 17.465 & 0.3099 & 23.030 \\
0.3389 & 4.781 & 0.5919 & 12.782 & 0.4971 & 18.206 & 0.3755 & 24.476 \\
0.3914 & 5.794 & 0.5963 & 13.505 & 0.4498 & 18.785 & 0.4832 & 26.120 \\
0.4365 & 6.777 & 0.5970 & 14.192 & 0.3991 & 19.249 & 0.6380 & 27.921 \\
0.4748 & 7.731 & 0.5945 & 14.841 & 0.3501 & 19.682 & 0.8444 & 29.844 \\
0.5070 & 8.654 & 0.5888 & 15.450 & 0.3090 & 20.191 & 1.0356 & 31.349 \\
\hline
\end{tabular}

Table 9d. Deflections for the 6.35 unit thick isotropic hinged cylindrical shell (computed by using $24 \times 24$ S4R elements and Riks method), see Figure 9a.

\begin{tabular}{|cc|cc|cc|cc|}
\hline $\mathrm{P} / \mathrm{P}_{\max }$ & $-\mathrm{W}_{\mathrm{C}}$ & $\mathrm{P} / \mathrm{P}_{\max }$ & $-\mathrm{W}_{\mathrm{C}}$ & $\mathrm{P} / \mathrm{P}_{\max }$ & $-\mathrm{W}_{\mathrm{C}}$ & $\mathrm{P} / \mathrm{P}_{\max }$ & $-\mathrm{W}_{\mathrm{C}}$ \\
\hline 0.0517 & 1.846 & 0.1671 & 15.501 & -0.1001 & 14.520 & -0.0006 & 24.824 \\
0.1182 & 5.271 & 0.1323 & 16.145 & -0.1142 & 14.451 & 0.0626 & 26.565 \\
0.1583 & 8.257 & 0.0923 & 16.602 & -0.1247 & 14.862 & 0.1427 & 28.302 \\
0.1837 & 10.799 & 0.0504 & 16.915 & -0.1288 & 15.778 & 0.2403 & 30.023 \\
0.1914 & 11.904 & 0.0083 & 17.008 & -0.1271 & 16.961 & 0.3559 & 31.720 \\
0.1953 & 12.892 & -0.0312 & 16.697 & -0.1196 & 18.320 & 0.4898 & 33.388 \\
0.1950 & 13.752 & -0.0622 & 15.780 & -0.1055 & 19.817 & 0.6417 & 35.024 \\
0.1901 & 14.472 & -0.0739 & 15.206 & -0.0825 & 21.420 & 0.8114 & 36.626 \\
0.1806 & 15.050 & -0.0861 & 14.767 & -0.0484 & 23.100 & 1.0313 & 38.450 \\
\hline
\end{tabular}

Table 9e. Deflections for the 6.35 unit thick $\left[0^{0} / 90^{0} / 0^{0}\right]$ hinged cylindrical shell (computed by using $24 \times 24$ S4R elements and Riks method), see Figure 9a.

\begin{tabular}{|cc|cc|cc|cc|}
\hline $\mathrm{P} / \mathrm{P}_{\max }$ & $-\mathrm{W}_{\mathrm{C}}$ & $\mathrm{P} / \mathrm{P}_{\max }$ & $-\mathrm{W}_{\mathrm{C}}$ & $\mathrm{P} / \mathrm{P}_{\max }$ & $-\mathrm{W}_{\mathrm{C}}$ & $\mathrm{P} / \mathrm{P}_{\max }$ & $-\mathrm{W}_{\mathrm{C}}$ \\
\hline 0.0423 & 3.414 & -0.0817 & 15.574 & 0.0593 & 11.860 & -0.0731 & 17.712 \\
0.0765 & 8.834 & -0.0779 & 12.857 & 0.0428 & 10.506 & -0.0593 & 20.694 \\
0.0782 & 12.280 & -0.0650 & 10.991 & 0.0210 & 10.406 & -0.0214 & 24.230 \\
0.0564 & 14.492 & -0.0442 & 10.126 & -0.0006 & 10.745 & 0.0556 & 27.809 \\
0.0271 & 16.397 & -0.0189 & 10.494 & -0.0215 & 11.263 & 0.1700 & 31.174 \\
-0.0059 & 18.017 & 0.0007 & 11.931 & -0.0419 & 11.861 & 0.3213 & 34.362 \\
-0.0240 & 18.602 & 0.0142 & 13.623 & -0.0607 & 12.555 & 0.5085 & 37.394 \\
-0.0436 & 18.875 & 0.0296 & 14.751 & -0.0742 & 13.602 & 0.7292 & 40.274 \\
-0.0657 & 18.365 & 0.0499 & 14.425 & -0.0780 & 15.332 & 1.0243 & 43.444 \\
\hline
\end{tabular}


Table 9f. Deflections for the 6.35 unit thick $\left[90^{\circ} / 0^{0} / 90^{0}\right]$ hinged cylindrical shell (computed by using $24 \times 24$ S4R elements and Riks method), see Figure $9 \mathrm{a}$.

\begin{tabular}{|cc|cc|cc|cc|}
\hline $\mathrm{P} / \mathrm{P}_{\max }$ & $-\mathrm{W}_{\mathrm{C}}$ & $\mathrm{P} / \mathrm{P}_{\max }$ & $-\mathrm{W}_{\mathrm{C}}$ & $\mathrm{P} / \mathrm{P}_{\max }$ & $-\mathrm{W}_{\mathrm{C}}$ & $\mathrm{P} / \mathrm{P}_{\max }$ & $-\mathrm{W}_{\mathrm{C}}$ \\
\hline 0.0490 & 2.699 & 0.1499 & 18.140 & -0.0117 & 14.369 & -0.0402 & 22.448 \\
0.0822 & 5.205 & 0.1385 & 18.954 & -0.0168 & 13.519 & 0.0036 & 24.905 \\
0.1063 & 7.479 & 0.1222 & 19.416 & -0.0297 & 13.456 & 0.0693 & 27.427 \\
0.1249 & 9.527 & 0.1019 & 19.429 & -0.0458 & 13.873 & 0.1598 & 29.941 \\
0.1393 & 11.374 & 0.0792 & 19.167 & -0.0619 & 14.469 & 0.2761 & 32.401 \\
0.1498 & 13.043 & 0.0331 & 18.249 & -0.0752 & 15.258 & 0.4180 & 34.786 \\
0.1562 & 14.550 & 0.0134 & 17.555 & -0.0818 & 16.461 & 0.5847 & 37.088 \\
0.1585 & 15.905 & -0.0011 & 16.641 & -0.0792 & 18.129 & 0.7747 & 39.301 \\
0.1565 & 17.107 & -0.0088 & 15.532 & -0.0663 & 20.157 & 1.0234 & 41.773 \\
\hline
\end{tabular}

\section{CLOSURE}

From more than forty publications on geometric nonlinear analysis of shells, eight sets of popularly employed benchmark problems are identified and the detailed reference solutions are tabulated. It is hoped that the solutions will form a convenient basis for subsequent comparison and that the inaccurate and time consuming task of reconstructing data points by graphical measurement of previously reported load-deflection curves can be avoided. To reveal the relative convergent difficulty, the number of load increments (NINC) and the number iterations (NITER) required by an automatic load incrementation scheme to attain the maximum loads are also reported. Care has been exercised to ensure that the reported solutions have been highly converged with respect to the mesh density. It is interesting to note that once the employed mesh becomes sufficiently fine, the NINC and the NITER are not sensitive to further mesh refinement. In view of converging difficulty, the most demanding problems are the cantilever subjected to end moment and the hinged cylindrical roofs. While the hinged roof problems must be solved by Riks method, NINC and NITER of the cantilever problem are significantly higher than that of the remaining benchmark cases.

Acknowledgment - The financial support of the William Mong Engineering Research Fund in form of a young researcher award to the second author is gratefully acknowledged. Mr.W.K.Chan is thanked for preparing some of the preliminary ABAQUS input date files. 


\section{REFERENCES}

1. MacNeal RH, Harder RL. A proposed standard set of problems to test finite element accuracy. Finite Elements in Analysis \& Design, 1, 3-20 (1985)

2. Hitchings D, Kamoulakos A, Davies GAO. Linear statics benchmarks. National Agency for Finite Element Methods \& Standards, Glasgow, UK, 1987.

3. Prinja NK, Clegg RA. Assembly benchmark tests for 3-D beams and shells exhibiting geometric non-linear behaviour, NAFEMS, Glasgow, UK, 1993.

4. Sabir AB, Lock AC, The application of finite elements to the large deflection geometrically nonlinear behaviour of cylindrical shells. Variational Methods in Engineering, ed. by Brebbia CA, Tottenham H, Southampton University Press, 7/54-7/65, 1972.

5. Horrigmoe G, Bergan PG. Nonlinear analysis of free-from shells by flat finite elements. Computer Methods Appl.Mech.Engrg., 16: 11-35 (1978)

6. Hughes TJR, Liu WK. Nonlinear finite element analysis of shells: Part I. Three-dimensional shells. Computer Methods Appl.Mech.Engrg., 26: 331-362 (1981)

7. Crisfield MA. A fast incremental/iterative solution procedure that handles "snap-through". Computers \& Structures, 13: 55-62 (1981)

8. Parisch H. Large displacements of shells including material nonlinearities. Computer Methods Appl.Mech.Engrg., 27: 183-214 (1981)

9. Surana KS. Geometrically non-linear formulation for the three dimensional solid-shell transition finite elements. Computers \& Structures, 15: 549-566 (1982)

10. Surana KS. Geometrically nonlinear formulation for curved shell elements. Inter. J. Numer. Methods Engrg., 19: 581-615 (1983)

11. Oliver J, Onate E. A total Lagrangian formulation for the geometrically nonlinear analysis of structures using finite elements. Part I. Two-dimensional problems: shell and plate structures. Inter.J. Numer.Methods Engrg., 20: 2253-2281 (1984)

12. Saigal S, Kapania R, Yang Y. Geometric nonlinear finite element analysis of imperfect laminated shells. J. Composite Mater., 20: 197-214 (1986)

13. Simo JC, Vu-Quoc L. A three-dimensional finite strain rod model, Part II: computational aspects. Computer Methods Appl.Mech.Engrg., 58: 79-116 (1986)

14. Gruttmann F, Stein E, Wriggers P. Theory and numerics of thin elastic shells with finite rotations. Ingenieur-Archiv, 59: 54-67 (1989)

15. Yeom CH, Lee SW. An assumed strain finite element model for large deflection composite shells. Inter.J.Numer.Methods Engrg., 28: 1749-1768 (1989)

16. Stander N, Matzenmiller A and Ramm E. An assessment of assumed strain method in finite rotation shell analysis. Engrg. Comput., 6: 58-66 (1989)

17. Hsiao KM, Chen YR. Nonlinear analysis of shell structures by degenerated isoparametric shell element. Computers \& Structures, 31: 427-438 (1989)

18. Simo JC, Fox DD and Rifai MS. On a stress resultant geometrically exact shell model. Part III: Compuational aspects of the nonlinear theory. Computer Methods Appl.Mech.Engrg., 79: 21-70 (1990)

19. Simo JC, Rifai MS and Fox DD. On a stress resultant geometrically exact shell model. Part IV: Variable thickness shells with through-the-thickness stretching. Computer Methods Appl.Mech. Engrg., 81: 91-126 (1990)

20. Laschet G, Jeusette, JP. Postbuckling finite element analysis of composite panels. Compos. Structure, 14: 35-48 (1990)

21. Saleeb AF, Chang TY, Graf W, Yingyeunyong S. A hybrid/mixed model for non-linear shell analysis and its applications to large-rotation problems. Inter.J.Numer.Methods Engrg., 29: 407-446 (1990)

22. Parisch H. An investigation of a finite rotation four node assumed strain shell element. Inter.J. Numer.Methods Engrg., 31: 127-150 (1991) 
23. Buechter N, Ramm E. Shell theory versus degeneration-a comparison in large rotation finite element analysis. Inter.J.Numer.Methods Engrg., 34: 39-59 (1992)

24. Peng X, Crisfield MA. A consistent corotational formulation for shells using the constant stress/ constant moment triangle. Inter.J.Numer.Methods Engrg., 35: 1829-1847 (1992)

25. Basar Y, Ding Y. Finite-rotation shell elements for the analysis of finite-rotation shell problems. Inter.J.Numer.Methods Engrg., 34: 165-169 (1992)

26. Sansour C, Bufler H. An exact finite rotation shell theory, its mixed variational formulation and its finite element implementation. Inter.J.Numer.Methods Engrg., 34: 73-115 (1992)

27. Wriggers P, Gruttmann F. Thin shells with finite rotations formulated in Biot stress: Theory and finite element formulation. Inter.J.Numer.Methods Engrg., 36: 2049-2071 (1993)

28. Jiang L, Chernuka MW. A simple four-noded corotational shell element for arbitrarily large rotations. Computers \& structures, 53: 1123-1132 (1994)

29. To CWS and Liu ML. Hybrid strain based three node flat triangular shell elements II: numerical investigation of nonlinear problems. Computers \& Structures, 54: 1057-1076 (1995)

30. Flores FG, Onate E, Zarate F. New assumed strain triangles for non linear shell analysis. Computational Mechanics, 17: 107-114 (1995)

31. Parisch H. A continuum-based shell theory for non-linear applications. Inter.J.Numer.Methods Engrg., 38: 1855-1883 (1995)

32. Park HC, Cho C, Lee SW. An efficient assumed strain element model with six dof per node for geometrically nonlinear shells. Inter.J.Numer.Methods Engrg., 38: 4101-4122 (1995)

33. Brank B, Peric D, Damjanic FB. On implementation of a nonlinear four node shell finite element for thin multilayered elastic shells. Computational Mechanics, 16: 341-359 (1995)

34. Betsch P, Stein E. An assumed strain approach avoiding artificial thickness straining for a nonlinear 4-node shell element. Commun.Numer.Methods Engrg., 11: 899-909 (1995)

35. Betsch P, Gruttmann F, Stein E. A 4-node finite shell element for the implementation of general hyperelastic 3D-elasticity at finite strains. Computer Methods Appl.Mech.Engrg., 130: 57-79 (1996)

36. Barut A, Madenci E, Tessler A. Nonlinear analysis of laminates through a Mindlin-type shear deformable shallow shell element. Computer Methods Appl.Mech.Engrg., 143: 155-173 (1997)

37. Hauptmann R, Schweizerhof K. A systematic development of solid-shell element formulations for linear and non-linear analyses employing only displacement degrees of freedom. Inter.J.Numer.Methods Engrg., 42, 49-69 (1998)

38. Lee SJ, Kanok-Numkulchai. A nine-node assumed strain finite element for large-deformation analysis of laminated shells. Inter.J.Numer.Methods Engrg., 42: 777-798 (1998)

39. Sansour C, Bocko J. On hybrid stress, hybrid strain and enhanced strain finite element formulations for a geometrically exact shell theory with drilling degrees of freedom. Inter.J. Numer.Methods Engrg., 43: 175-192 (1998)

40. Mohan P, Kapania RK. Updated Lagrangian formulation of a flat triangular element for thin laminated shells. AIAA Journal, 36: 273-281 (1998)

41. Providas E, Kattis MA. A simple finite element model for the geometrically nonlinear analysis of thin shells. Computational Mechanics, 24: 127-137 (1999)

42. Klinkel S, Gruttmann F, Wagner W. A continuum based three-dimensional shell element for laminated structures. Computers \& Structures, 71: 43-62 (1999)

43. Sze KY, Zheng SJ. A hybrid stress nine-node degenerated shell element for geometric nonlinear analysis. Computational Mechanics, 23: 448-456 (1999)

44. Sansour C, Kollmann FG. Families of 4-node and 9-node finite elements for a finite deformation shell theory. An assessment of hybrid stress, hybrid strain and enhanced strain elements. Computational Mechanics, 24: 435-447 (2000)

45. El-Abbasi N, Meguid SA. A new shell element accounting for through-thickness deformation. Computer Methods Appl.Mech.Engrg., 189: 841-862 (2000) 
46. Hong WI, Kim JH, Kim YH, Lee SW. An assumed strain triangular curved solid shell element formulation for analysis for plates and shells undergoing finite rotations. Inter.J.Numer.Methods Engrg., 52: 747-761 (2001)

47. Sze KY, Zheng S-J. A stabilized hybrid-stress solid element for geometrically nonlinear homogeneous and laminated shell analyses. Computer Methods Appl.Mech.Engrg., 191: 19451966 (2002)

48. Sze KY, Chan WK, Pian THH. An eight-node hybrid-stress solid-shell element for geometric nonlinear analysis of elastic shells. Inter.J.Numer.Methods Engrg., 55: 853-878 (2002)

49. Kim CH, Sze KY, Kim YH. Curved quadratic triangular degenerated- and solid-shell elements for geometric nonlinear analysis. Inter.J.Numer.Methods Engrg., 57: 2077-2097 ( 2003)

50. ABAQUS. ABAQUS Theory and User's Manuals, Version 5.8, Hibbitt, Karlsson \& Sorensen, Inc., Pawtucket, Rhode Island, USA, 1998. 


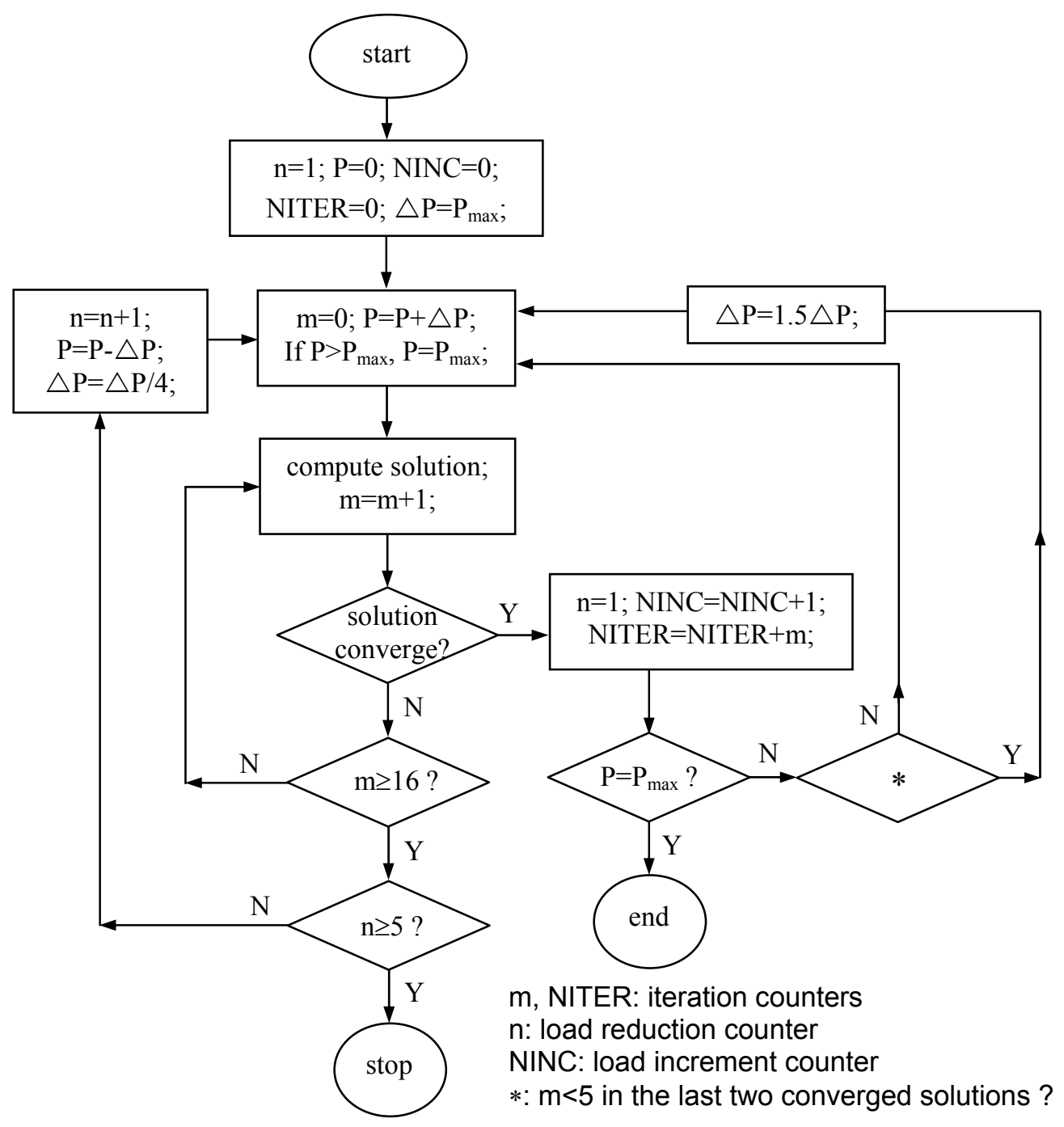

Figure 1. The automatic load incrementation scheme. 


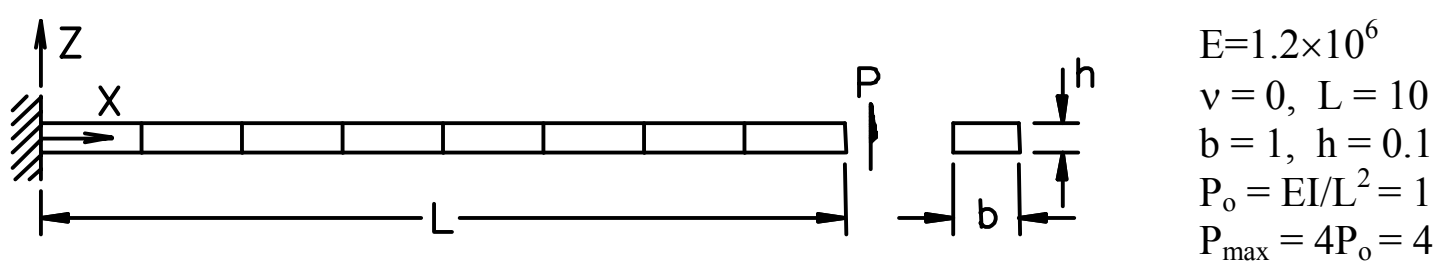

Figure 2a: Cantilever subjected to end shear force.

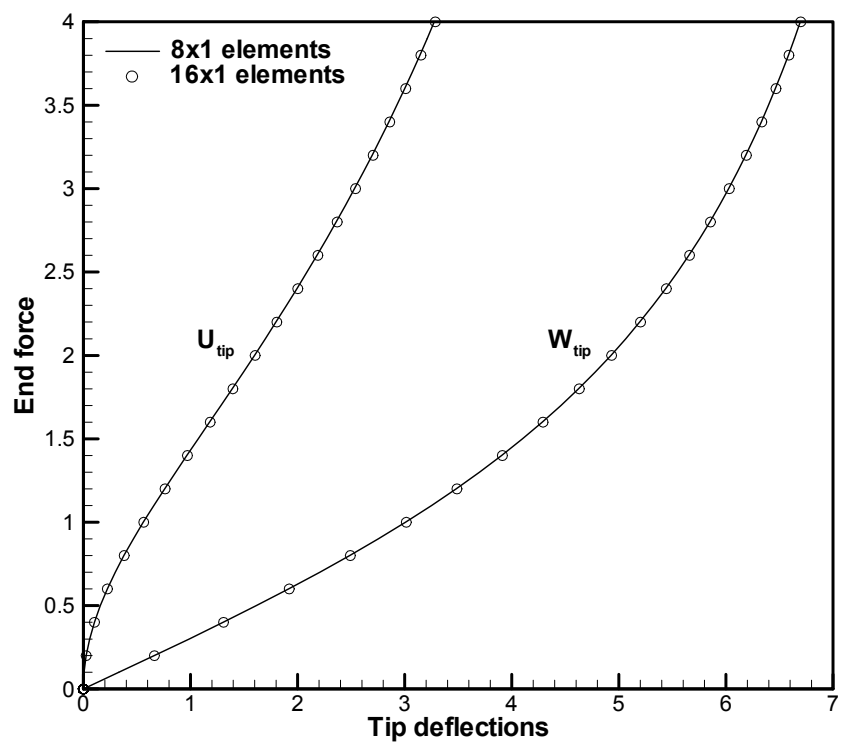

Figure 2b: Load-deflection curves for cantilever subjected to end shear force.

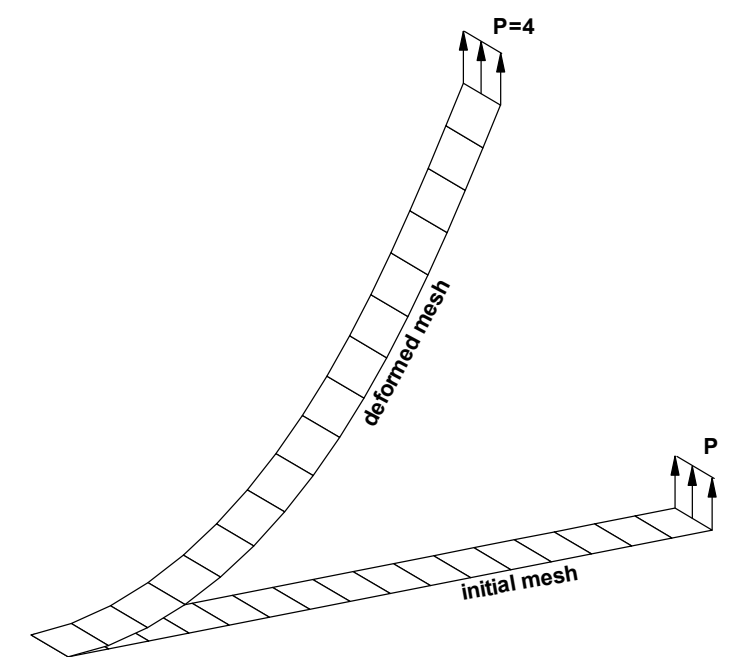

Figure 2c: The deformed $16 \times 1$ mesh under the maximum force. 


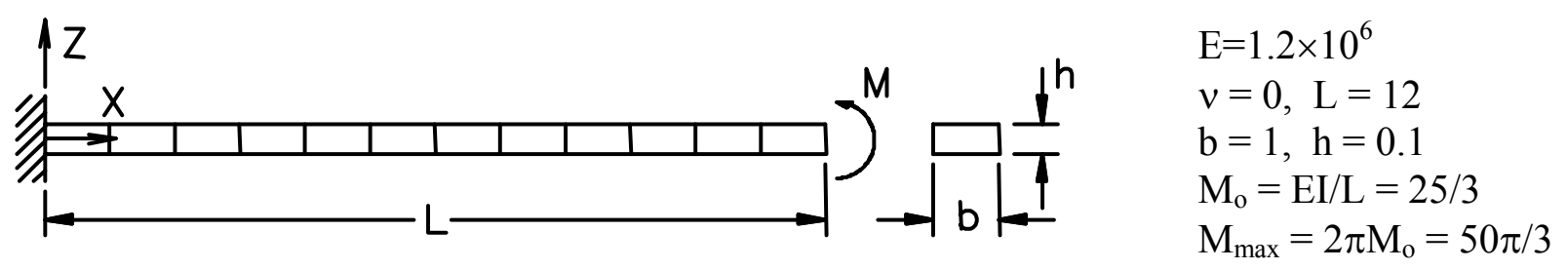

Figure 3a. Cantilever subjected to end bending moment.

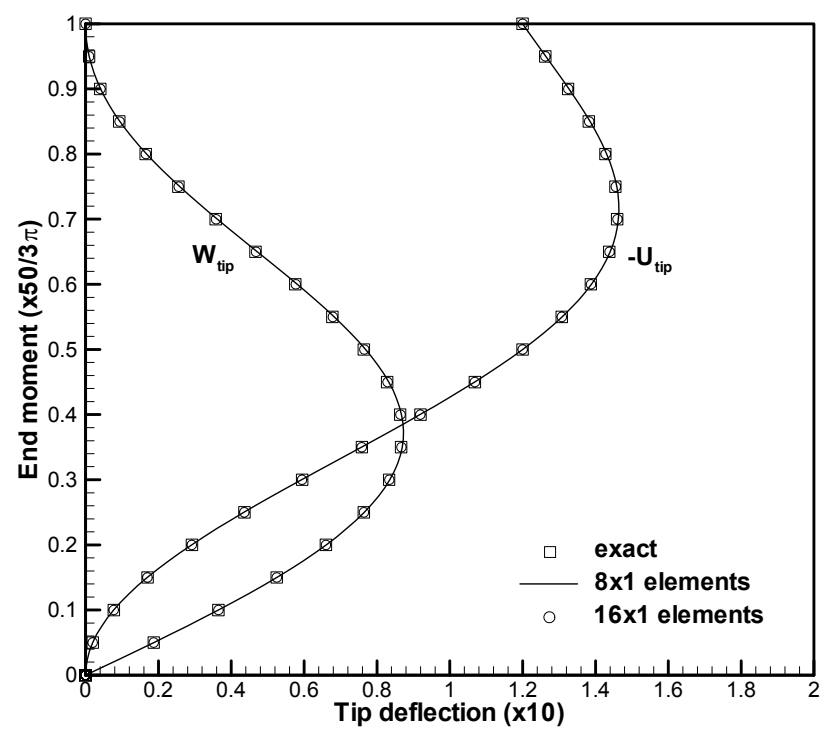

Figure 3b: Load-deflection curves for cantilever subjected to end bending moment.

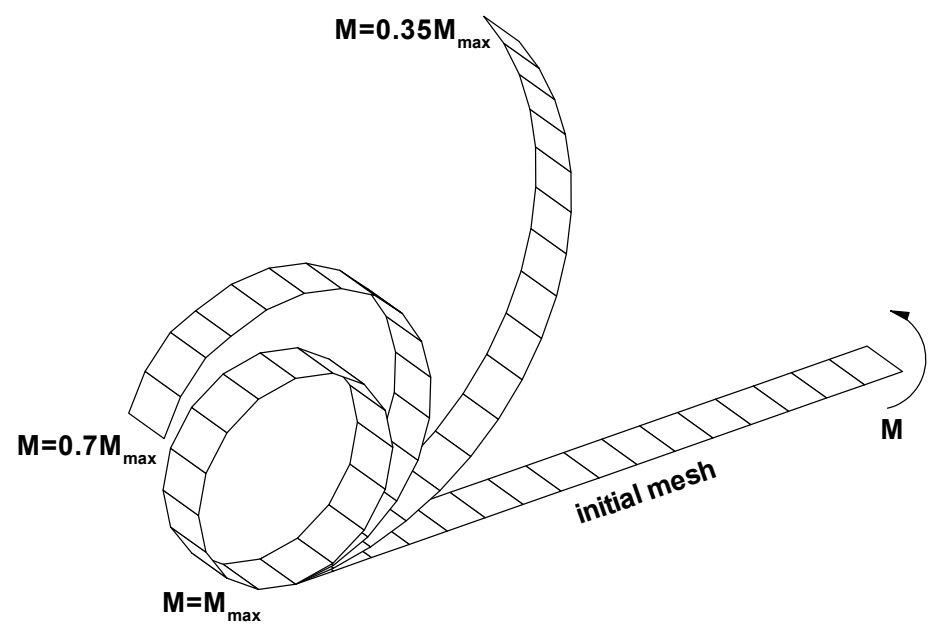

Figure 3c: The deformed $16 \times 1$ mesh under the maximum bending moment. 


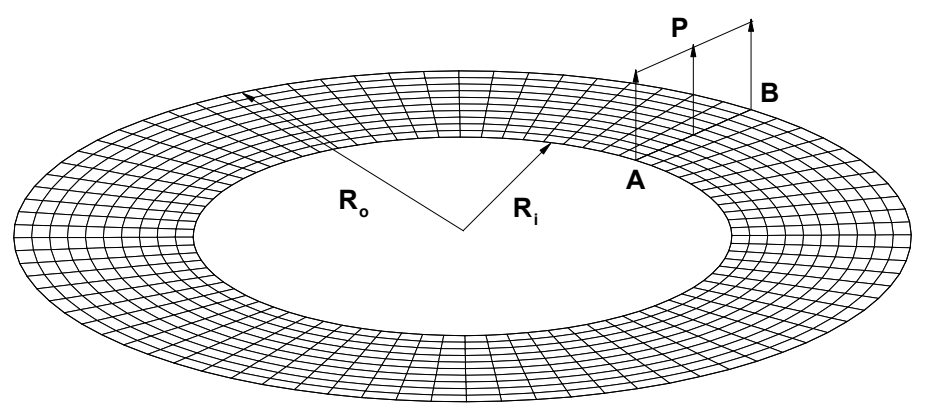

$$
\begin{aligned}
& E=21 \times 10^{6}, \\
& v=0 \\
& R_{i}=6, R_{o}=10 \\
& h=0.03 \\
& P_{\max }=0.8 \text { (force/length) }
\end{aligned}
$$

Figure 4a. The slit annular plate loaded with the line force P.

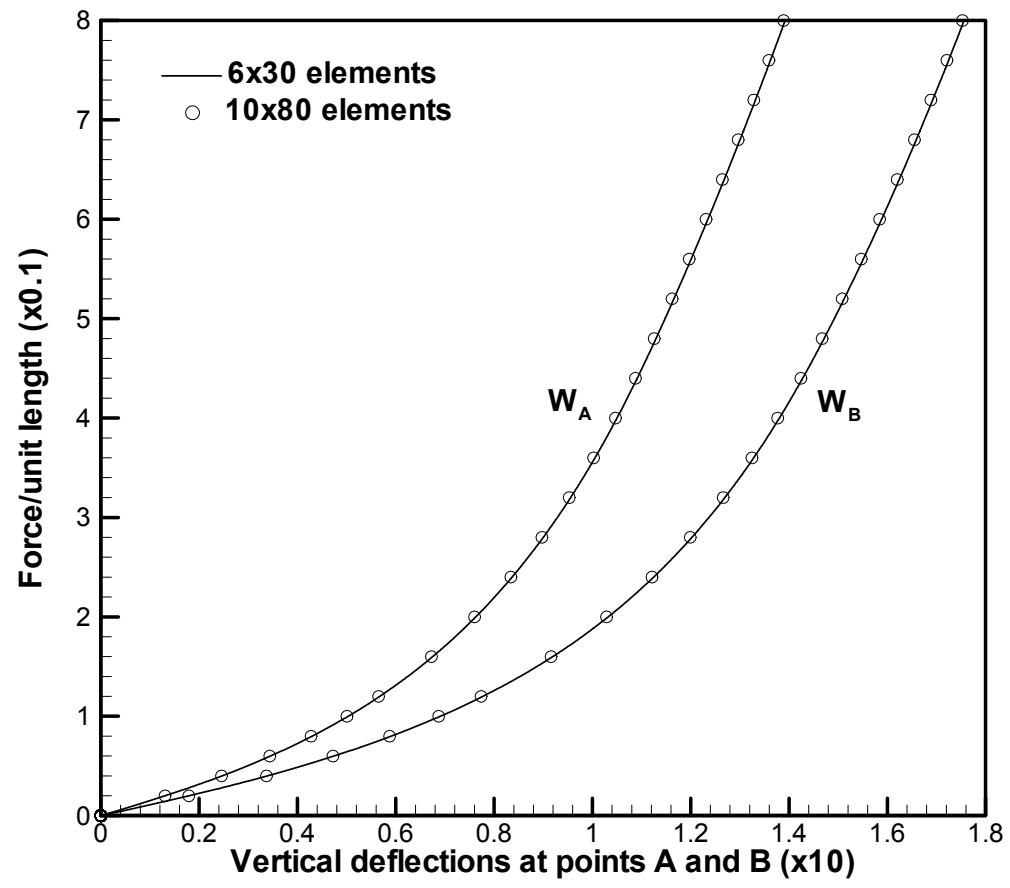

Figure 4b: Load-deflection curves for the slit annular plate lifted by line force $\mathrm{P}$.

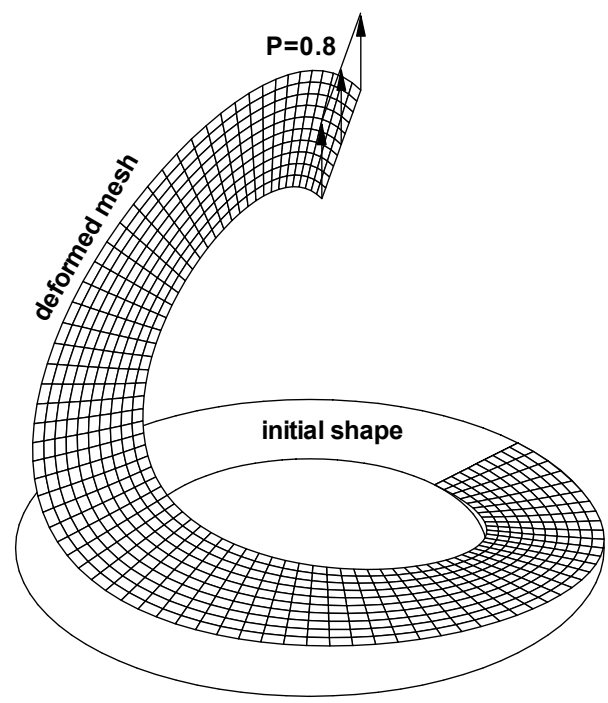

Figure 4c: The deformed $10 \times 80$ mesh at $\mathrm{P}=\mathrm{P}_{\max }$. 


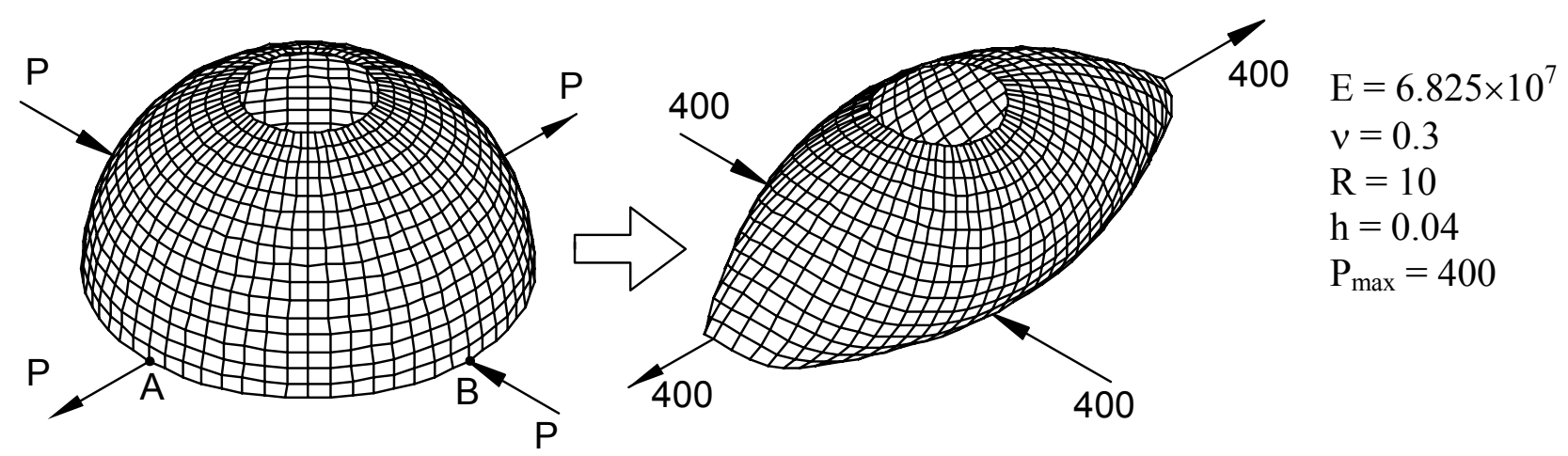

Figure 5a. The initial geometry and deformed geometry at $\mathrm{P}=\mathrm{P}_{\max }$ for the hemispherical shell subjected to inward and outward radial forces.

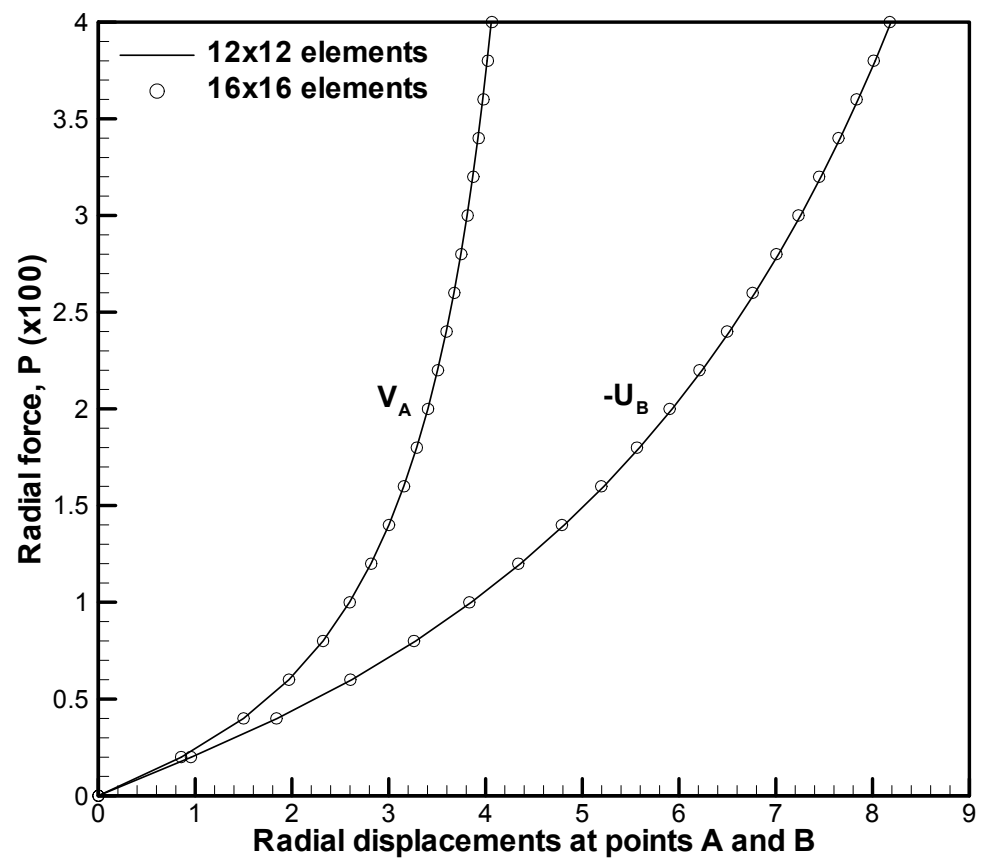

Figure 5b: Load-deflection curves for the hemisphere shell subjected to radial forces.

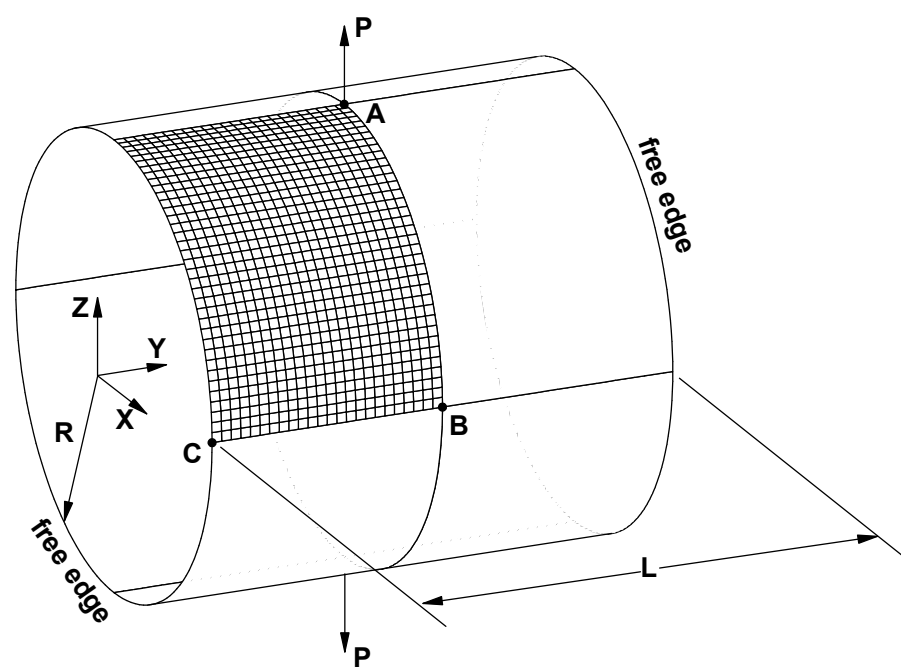

$$
\begin{aligned}
& E=10.5 \times 10^{6} \\
& v=0.3125 \\
& R=4.953 \\
& L=10.35 \\
& h=0.094 \\
& P_{\text {max }}=40,000
\end{aligned}
$$

Figure 6a: The open-end cylindrical shell subjected to radial pulling forces. 


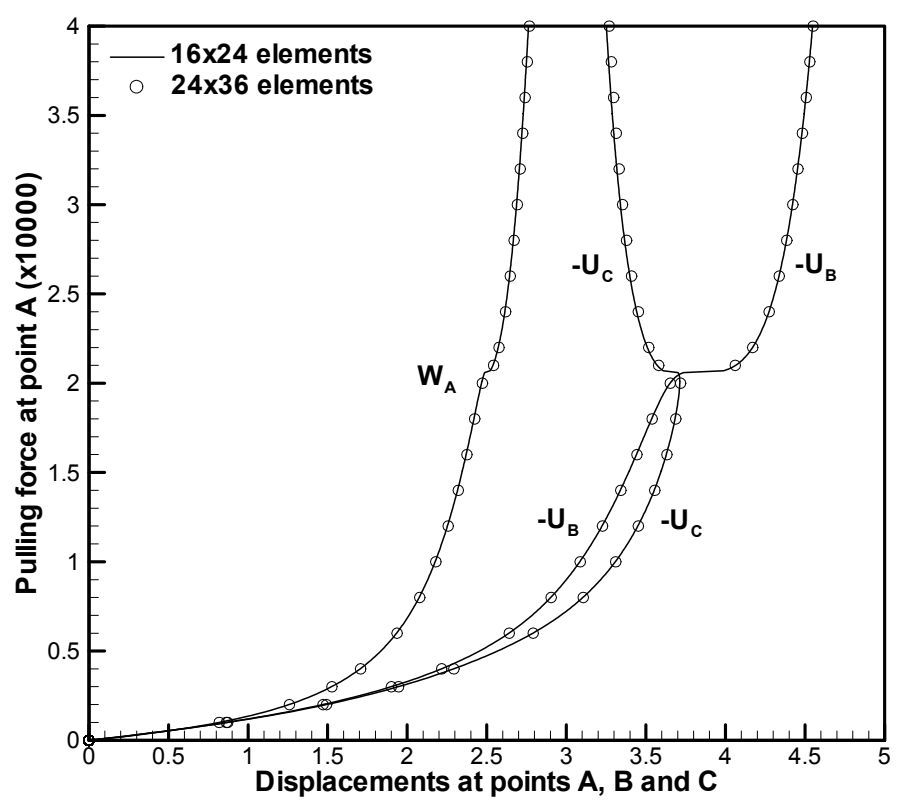

Figure 6b: Load-deflection curves of the open-end cylinder subjected to pulling forces.

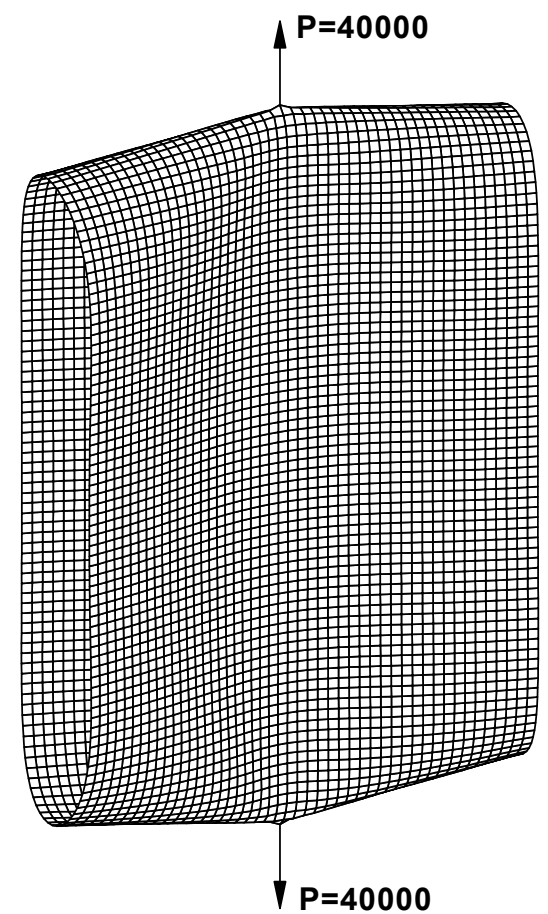

Figure 6c: The deformed $24 \times 36$ mesh for the open-ended cylindrical under the maximum load. 


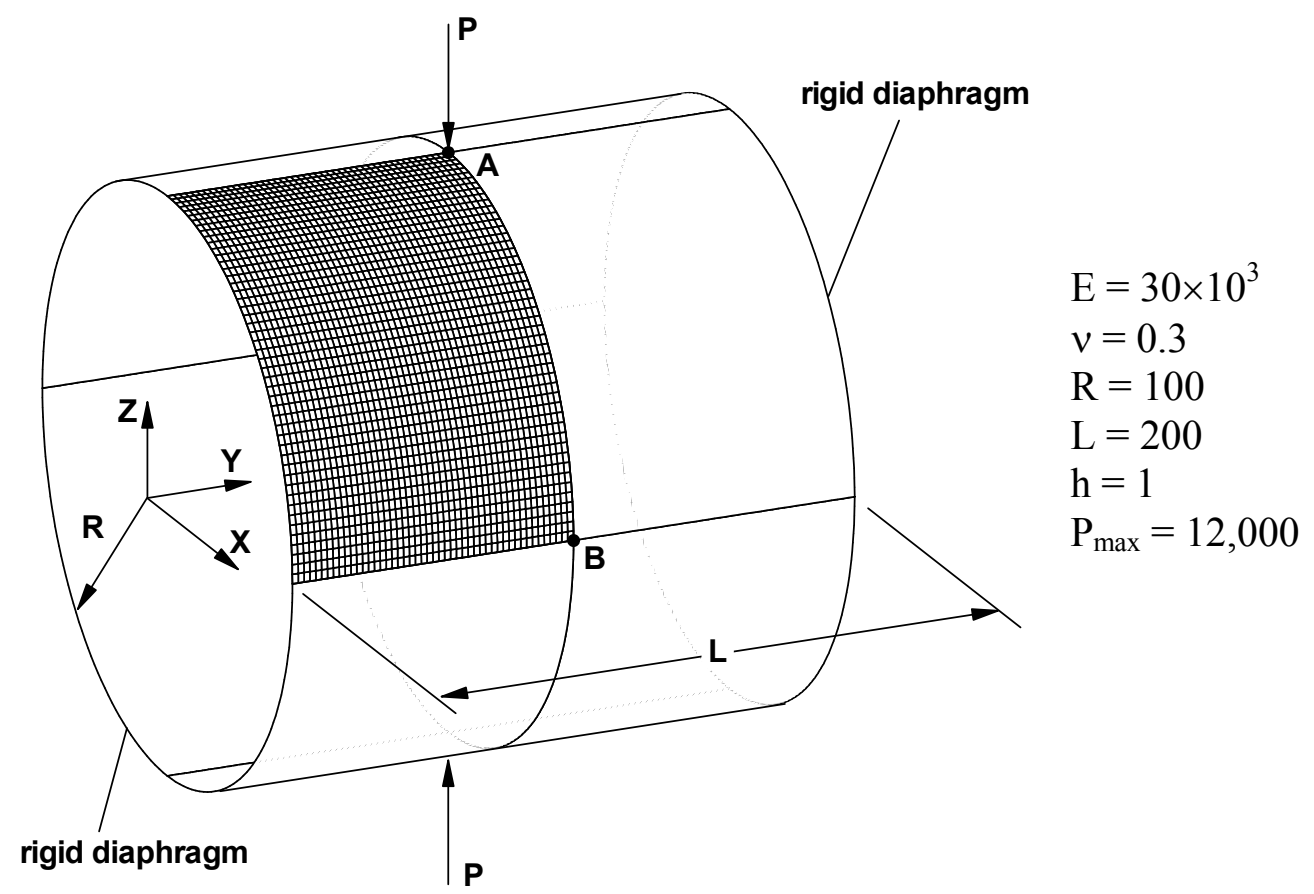

Figure 7a: Pinched cylindrical shell mounted on rigid end diaphragms.

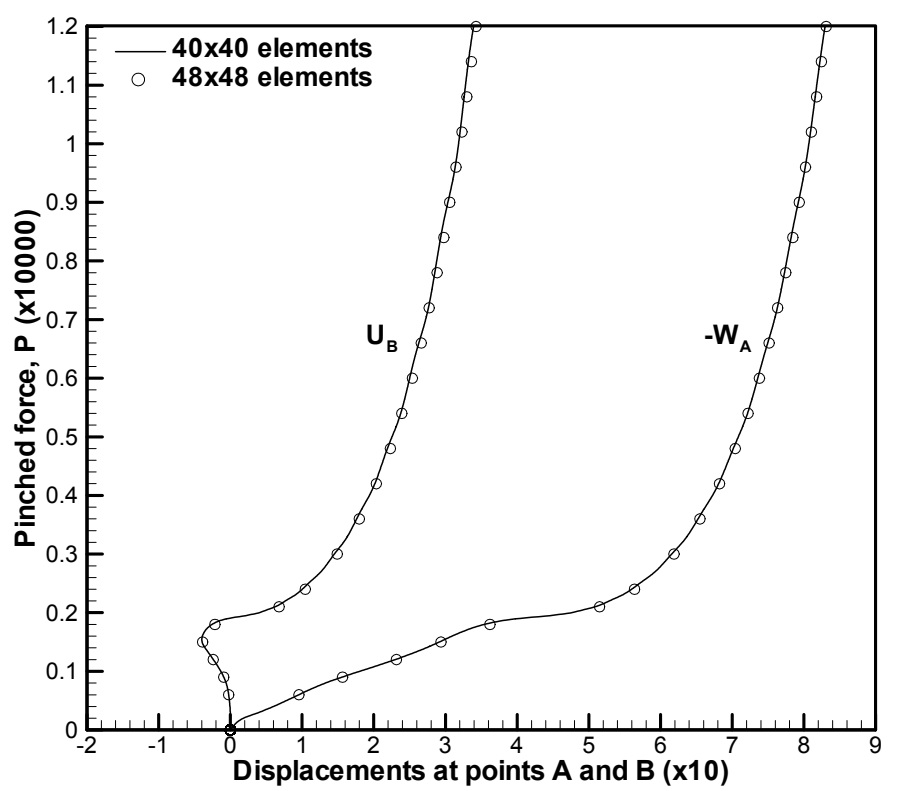

Figure 7b: Load-deflection curves of the pinched cylinder mounted over rigid end diaphragms. 


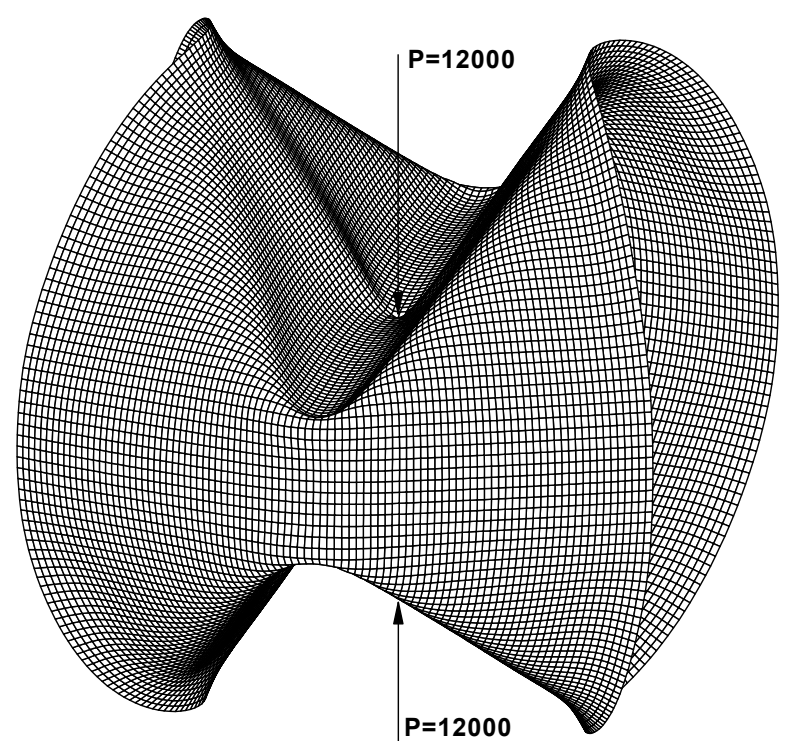

Figure $7 \mathrm{c}$ : The deformed $48 \times 48$ mesh of the pinched cylinder under maximum load.

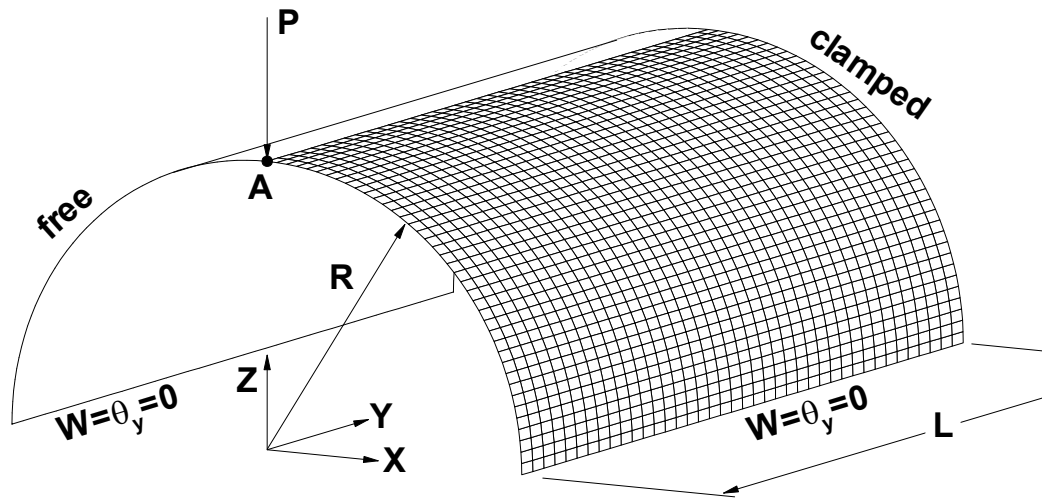

$\underline{\text { Isotropic Shell }}$

$$
E=2.0685 \times 10^{7}, v=0.3
$$

\section{$\underline{\text { Laminated Shell }}$}

$$
\begin{gathered}
\mathrm{E}_{\mathrm{L}}=2068.5, \mathrm{E}_{\mathrm{T}}=517.125 \\
\mathrm{G}_{\mathrm{LT}}=795.6, v_{\mathrm{LT}}=v_{\mathrm{TT}}= \\
0.3 \\
\text { lamination: }\left[0^{0} / 90^{0} / 0^{0}\right] \text { and } \\
{\left[90^{0} / 0^{0} / 90^{0}\right]}
\end{gathered}
$$

Figure $8 \mathrm{a}$. The semi-cylindrical shell subjected to an end pinching force.

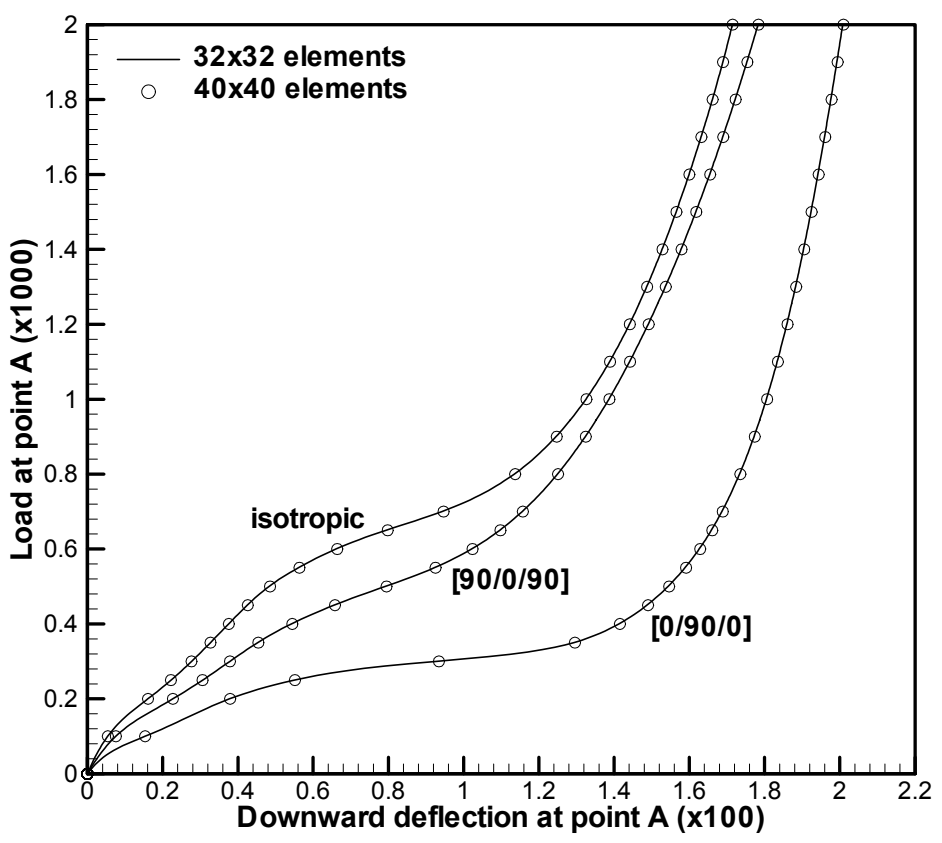


Figure 8b: Load-deflection curves of the semi-cylindrical shell subjected to end pinching force.

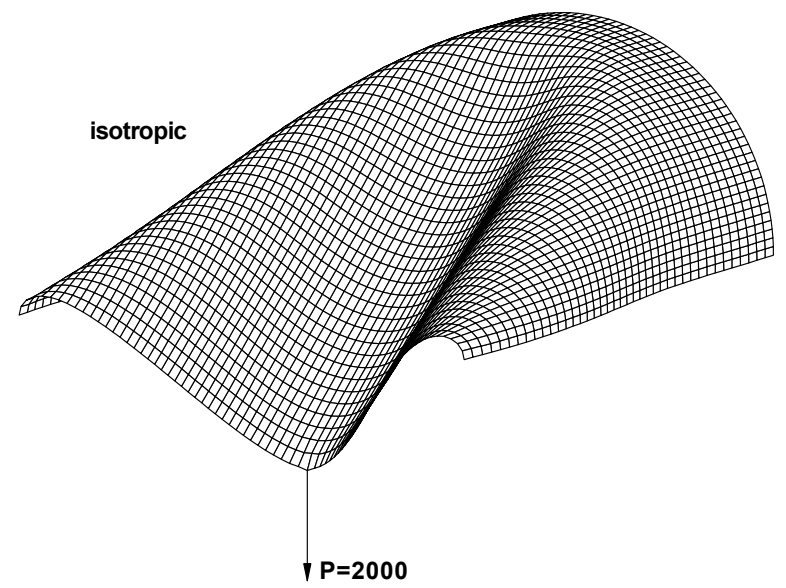

Figure $8 \mathrm{c}$. The deformed $40 \times 40$ mesh of the semi-cylindrical isotopic shell under maximum load.
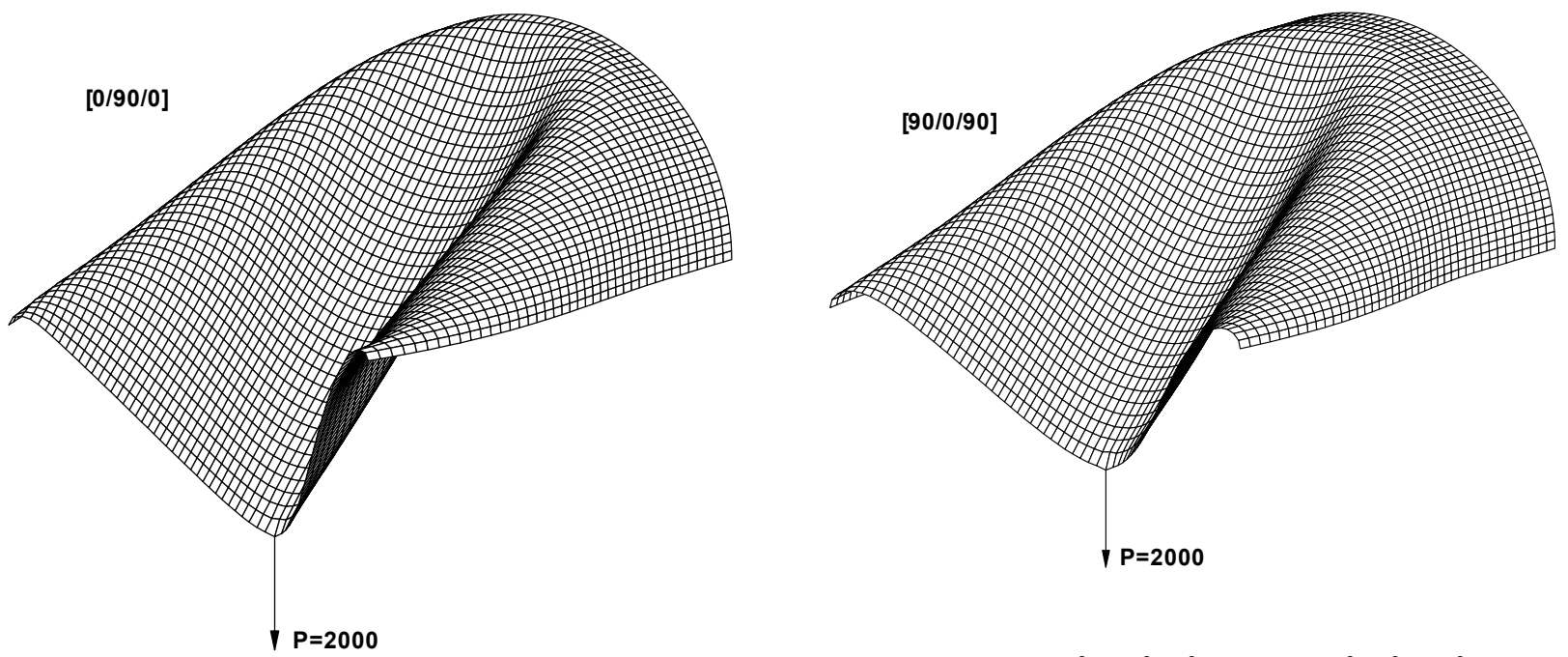

Figure 8d. The deformed $40 \times 40$ meshes of the semi-cylindrical $\left[0^{0} / 90^{\circ} / 0^{0}\right]$ and $\left[90^{\circ} / 0^{0} / 90^{0}\right]$ laminated shells under maximum load.

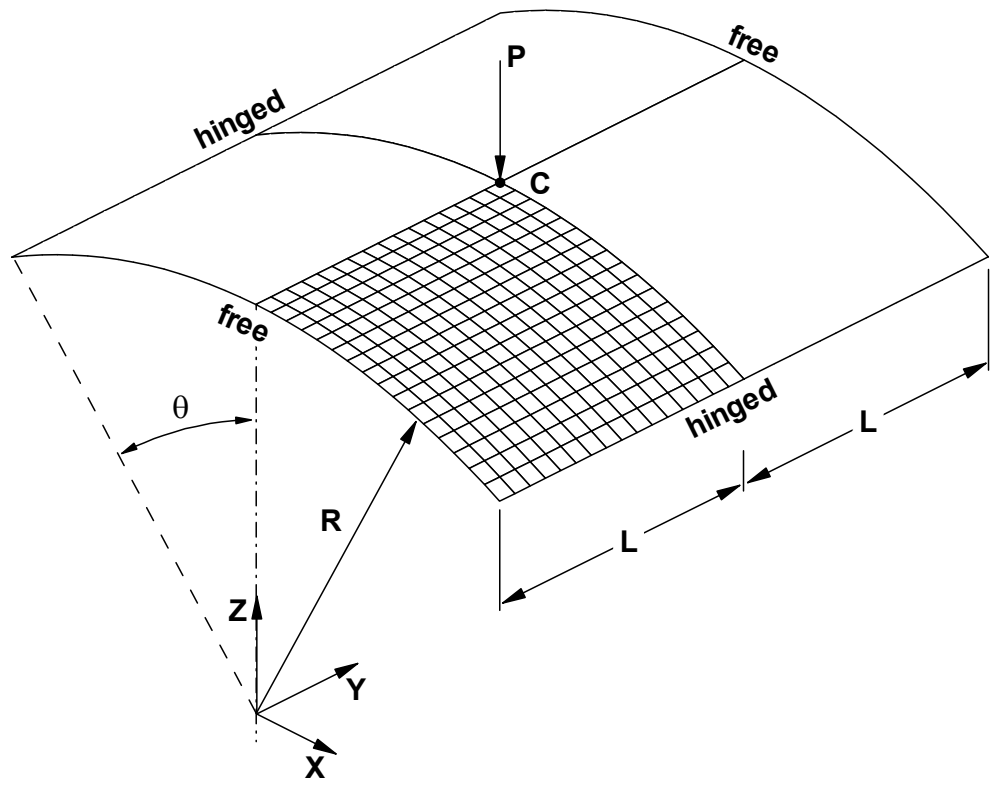

$\mathrm{R}=2540, \mathrm{~L}=254$

$\theta=0.1$ radian

$\mathrm{h}=12.7$ or 6.35

$\mathrm{P}_{\max }=3000$

Isotropic Shell

$\mathrm{E}=3102.75, v=0.3$

Laminated Shell

$\mathrm{E}_{\mathrm{L}}=3300, \mathrm{E}_{\mathrm{T}}=1100$

$\mathrm{G}_{\mathrm{LT}}=660, v_{\mathrm{LT}}=v_{\mathrm{TT}}=0.25$

lamination: $\left[0^{0} / 90^{0} / 0^{0}\right]$ and $\left[90^{\circ} / 0^{\circ} / 90^{\circ}\right]$

Figure 9a: Hinged cylindrical roof subjected to a central pinching force. 


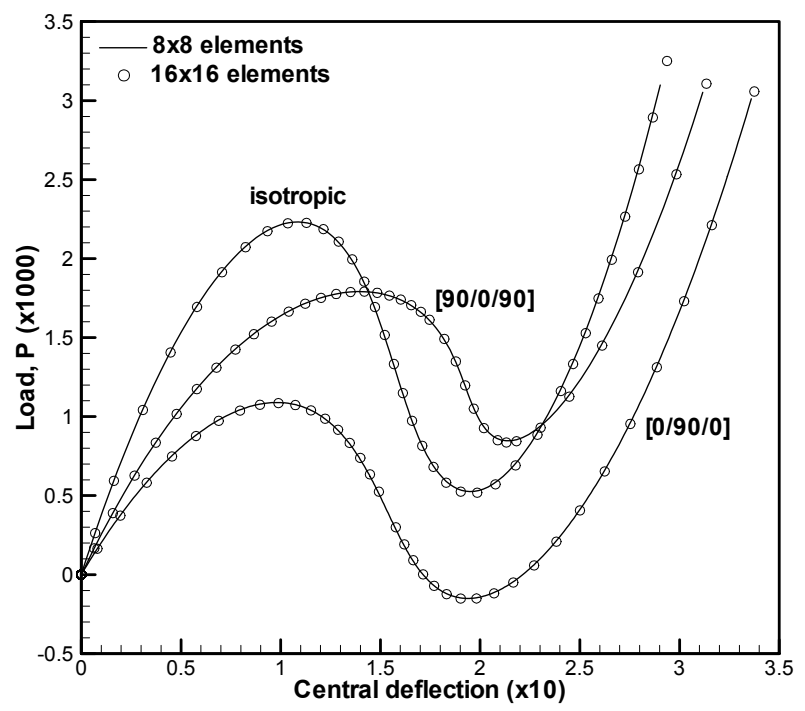

Figure 9b: Load-deflection curves of the 12.7 unit thick hinged cylindrical roof.
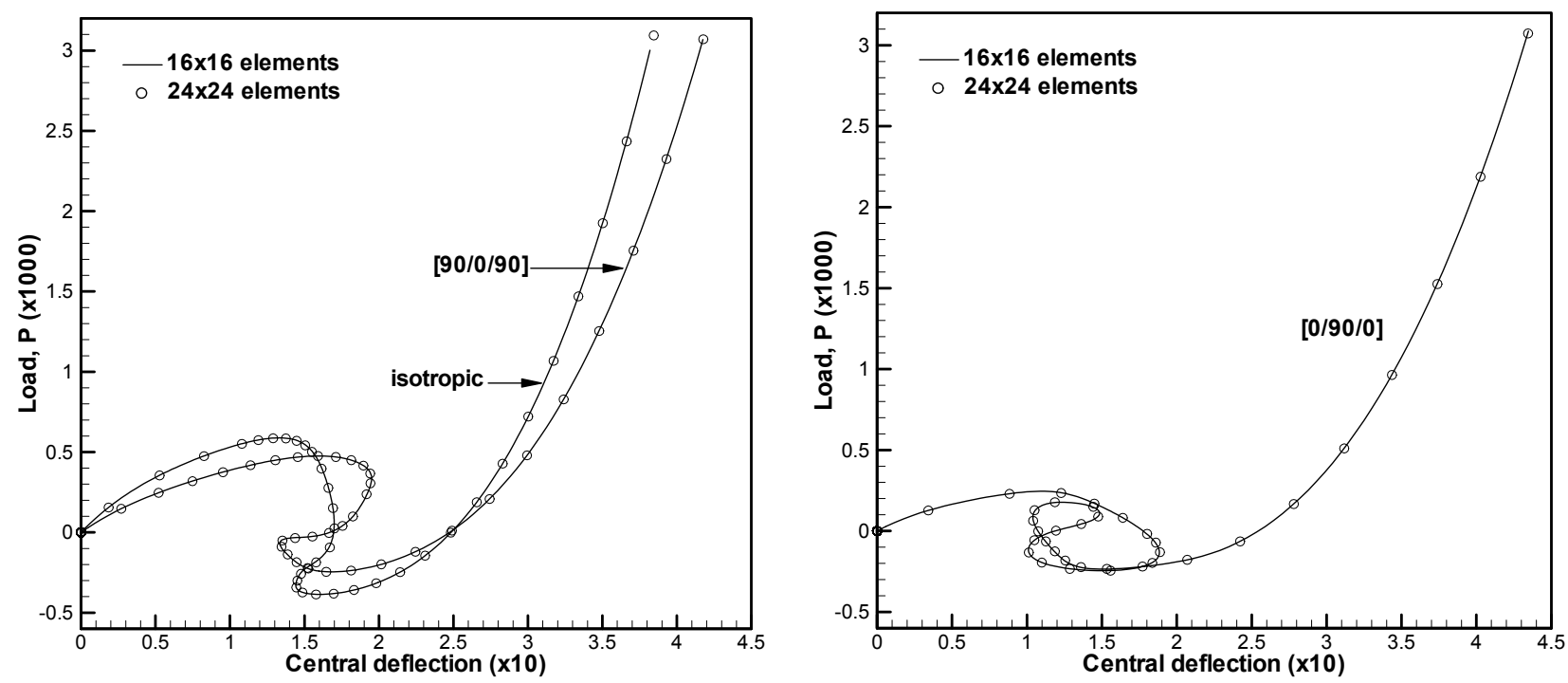

Figure 9c: Load-deflection curves of the 6.35 unit thick hinged cylindrical roof. 